\title{
Untersuchungen ïber die Beschaffenheit des Blutes von Schwangeren und Wöchnerinnen, sowie über die Zusammensetzung des Fruchtwassers und ihre gegenseitigen Beziehungen.
}

Von

Richard Schroeder,

prakt. Arzt ans Berlin.

Während man in früherer Zeit ohne weiteres eine Plethora der Schwangeren angenommen hatte, weil man von der Vorstellung ausging, dass das Blut derselben mehr Nahrungsstoffe enthalten müsse, als dasjenige von Nichtschwangeren, stellten besonders Andral und Gavarret (1840), Regnault, Becquerel und Rodier (1846) fest, dass das Blut Schwangerer sich im Gegentheile durch verminderte Anzahl der rothen Blutkörperchen und durch Vermehrung der Fibrin- und Wassermenge auszeichne. Charakteristisch sei also für die Schwangerschaft eine chlorotische Beschaffenheit des Blutes, und aus diesem Umstande heraus dïrfe man die die Schwangerschaft so häufig begleitenden functionellen Störungen erklären und dementsprechend therapeutisch in Angriff nehmen. Auch Scanzoni sprach sich sehr entschieden dafür aus, dass man eine chlorotische Beschaffenheit des Blutes Schwangerer als normal anzusehen habe. Ihm schliesst sich mit gewissen Abweichungen $\mathrm{Kiw}$ isch an. Um den bedeutenden Stoffverbrauch zu erklären, der durch die Ernährung der Frucht, die vermehrte Absonderung der Brust- und Speicheldrüsen, die oft starken Schweisse bedingt werde, nahm er eine von ihm sogenannte seröse Polyhämie der Schwangeren an, so gewissermaassen zwischen den beiden sich gegenüberstehenden Ansichten vermittelnd. Es folgten dann die experimentirenden Untersuchungen von Nasse, Spiegelberg und Gscheidlen, von Cohnstein, ferner die Arbeiten von Ingerslev, welcher Zählungen von 
Schroeder, Untersuchungen üb. d. Beschaffenheit des Blutes u. s. w. 307

Blutkörperchen vornahm. Schon 1836 hatte Nasse in seiner Schrift: „Das Blut" die Ergebnisse seiner an 27 Schwangeren gemachten Blutuntersuchungen niedergelegt, und fast 20 Jahre später konnte er, gestützt auf 37 neue Fälle, jene früheren bestätigen: Er hatte im wesentlichen festgestellt eine Verminderung des specifischen Gewichtes, besonders bis zum achten Monate der Schwangerschaft hin; ferner Zunahme des Fibringehaltes und endlich auch eine Verminderung des Gehaltes an Hämoglobin, damit übereinstimmend eine verminderte Zahl der rothen Blutkörperchen. Auch die Untersuchungen, die er an Hündinnen vor der Befruchtung, während der Tragzeit und nach dem Werfen anstellte, lieferten ihm dieselben Ergebnisse. Es schien somit festzustehen, dass man es in der That während der Schwangerschaft mit einem der Chlorose ähnlichen Zustande des Blutes zu schaffen habe, und man beeilte sich, hierin die Erklärung für die mancherlei Beschwerden der Schwangeren zu finden, welche so auffällig mit denen der Chlorotischen übereinstimmten.

Indessen brachten erneute Untersuchungen über denselben Gegenstand ganz andere Ergebnisse. Man hatte inzwischen gelernt, die Gesammtblutmenge zu bestimmen, und mehr noch als die früheren Forscher lenkte man jetzt seine Aufmerksamkeit der Bestimmung des Hämoglobingehaltes und der Zählung der rothen Blutkörperchen zu. So fanden Spiegelberg und Gscheidlen, welche ebenfalls mit trächtigen Hündinnen Versuche machten, dass die Blutmenge während der zweiten Hälfte der Schwangerschaft beständig zunehme, dass das Hämoglobin gleichfalls eher vermehrt sei, auf jeden Fall nicht vermindert, und dass der Wassergehalt, wenn überhaupt, so nur sehr unbedeutend vermehrt sei. Auch Cohnstein stellte bei trächtigen Schafen fest, dass der Hämoglobingehalt erhöht sei, fand jedoch gleichzeitig eine Verminderung in der Anzahl der rothen Blutkörperchen. In gerslev suchte der streitigen Frage auf andere Weise näher zu treten. Er benutzte die Methode der Blutkörperchenzählung und bestimmte zunächst aus 10 Untersuchungen nichtschwangerer Frauen als Mittelzahl 5,59 Millionen pro $1 \mathrm{cmm}$ Blut. Aus 22 Untersuchungen gesunder Schwangerer fand er im Mittel 5,43 Millionen Blutkörperchen, somit ein Mehr von 0,16 Millionen zu Gunsten der Nichtschwangeren, indess schreibt er diesen doch recht unbedeutenden Unterschied dem Umstande zu, dass jene schwangeren Frauen einer sehr dürftig lebenden Volksklasse angehörten. 
Aus weiteren 18 Untersuchungen solcher Schwangeren, welcho ein besonders elendes und kränkliches Aussehen boten, bestimmte er uls Mittel 4,93 Millionen, als Gesammtmittel aus allen 40 Fällen 5,20 Millionen. Ex kommt schliesslich auf Grund dieser Untersuchungen zu dem Ergebnisse, dass wir nicht berechtigt seien, von einer Hydrämie der Schwangeren zu reden, dass die geringen Unterschiede auf die bei weitem ungünstigeren Lebensverhältnisse seiner Schwangeren zurückgeführt werden müssten.

Es bestand sonach ein entschiedener Gegensatz in den Anschauungen, die sich allmälig ïber die Blutbeschaffenheit Schwangerer herausgebildet hatten. Die Aelteren behaupteten oine Hydrämie oder Chloroanämie der Schwangeren, während die neueren Untersuchungen eine solche zum mindesten zweifelhaft erscheinen liessen, ja vielleicht, wenn man die an trächtigen Thieren gemachten Erfahrungen auf das menschliche Weib übertragen dürfte, was ja an sich keinenfalls unpassend erscheint, das Gegentheil sehr wahrscheinlich machten. Es waren jetzt aber neue vereinfachte Untersuchungsmethoden bekannt geworden, welche es ermöglichten, an einer und derselben Person wiederholt Blutentziehungen vorzunehmen, ohne dass man befürchten musste, sei es den Betreffenden in seiner Gesundheit zu schädigen, sei es die Beschaffenheit des Blutes selbst durch mehrmalige Blutentziehungen derart zu ändern, dass man gar nicht mehr die Folgen der letzteren von den zu erforschenden physiologischen oder pathologischen Aenderungen zu trennen vermöchte. Schon Spiegelberg und Gscheidlen hatten ihre Hämoglobinbestimmungen nach der spectroskopischen Titrirmethode Prey er's angestellt. Wesentlich vereinfacht wurden diese Untersuchungen, als $\mathrm{V}$ i er o $\mathrm{rdt}$ die quantitative Spectralanalyse, die Photometrie der Absorptionsspectren entdeckte. (Vierordt: „Die Anwendung des Spectralapparates zur Messung und Vergleichung des farbigen Lichtes." Tübingen 1871. - „Die Anwendung des Spectralapparates zur Photometrie der Absorptionsspectren." Tübingen 1873.) Mit diesem Apparate war der wissenschaftlichen Forschung auf diesem Gebiete ein äusserst wichtiges und förderndes Werkzeug in die Hand gegeben, mit ihm wurden die umfangreichen und grundlegenden Untersuchungen Leichtenstern's über die Physiologie und Pathologie des Blutes vorgenommen, durch welche unzweideutig festgestellt werden konnte, welchen bedeutenden Einfluss auf die Blutbeschaffenheit die verschiedensten individuellen Ver- 
hältnisse haben, welchen Unterschied Körperbeschaffenheit, Nahrungsweise, Geschlecht, Alter u. s. w. bedingen. Es ist zu bedauern, dass Leichtenstern in den Kreis seiner Untersuchungen nicht auch Schwangere einbezogen hat, da wir von einem so sorgfältigen und geïbten Untersucher sehr schätzbare Ergebnisse zu erwarten gehabt hätten. Einen sehr wesentlichen Vortheil hat mit der Methode der quantitativen Spectralanalyse gemeinsam ein anderes Verfahren, welches von v. Fleischl (Medicinische Jahrbïcher. Wien 1886) angegeben wurde. Es möge mir gestattet sein, an späterer Stelle, wenn ich zu meinen eigenen Untersuchungen übergehe, einige wenige Worte über den Grundgedanken und den Gebrauch des Hämometers von Fleischl anzuführen.

Mit diesem Apparate arbeitete zuerst Fehling. Er war unserer Frage von einem ganz anderen Gesichtspunkte aus näher getreten. Ihm lag daran, festzustellen, ob zwischen der Blutbeschaffenheit bei Schwangeren und der Zusammensetzung des Fruchtwassers irgendwelche Beziehungen vorhanden sind, insbesondere ob zwischen dem Hämoglobingehalte und dem Gehalte des Fruchtwassers an Eiweiss ein Verhältniss bestehe, indem er zugleich dadurch in die Frage nach der Bedeutung des Fruchtwassers, welche durch Gusserow, Ahlfeld und Andere wieder mehr erörtert worden war, Licht zu bringen hoffte. Fleischl hatte bei gesunden Männern den Hämoglobinwerth des Blutes $=100$ gesetzt, bei Frauen $=93$. Fehling nun fand bei seinen etwa 100 Hämoglobinbestimroungen im Blute der Schwangeren in $2 / 3$ der Fälle den Hämoglobinwerth unter 100, in $1 / 3$ der Fälle über 100. Während der Hämoglobingehalt zwischen 67-110 Proc. schwankte, wurde ein Mittelwerth von 93 Proc. festgestellt, also übereinstimmend mit dem von Flei schl für nichtschwangere Frauen gefundenen. Fehling selber macht sich den Einwand, ob die immerhin auffällig hohen Hämoglobinwerthe, die so oft die des gesunden Mannes übertrafen, in der That vorhanden und eine Folge der Schwangerschaft seien, oder ob sie vielleicht nur auf einer fehlerhaften Aichung der Blutpipette beruhten. Von grösserem Interesse und Werthe sind jedoch jene Ergebnisse, die sich bei mehrfach an derselben Schwangeren in Zwischenräumen von acht zu acht Tagen vorgenommenen Untersuchungen herausstellten. Hierbei wurde fast durchweg eine bedeutende Steigerung des Hämoglobingehaltes beobachtet; nur in etwa $1 / 4$ der Fälle blieb die Hämoglobinmenge gleich oder 
nahm wenig ab. Fehling hatte zugleich mit der Hämoglobinbestimmung Zählungen der rothen Blutkörperchen vorgenommen, und auch hier konnte er bei wiederholten Untersuchungen eine Vermehrung ihrer Zahl nachweisen. Er ist geneigt, diese Steigerung der wichtigsten Blutbestandtheile zum Theile aus dem Umstande zu erklären, dass die Betreffenden aus zweifellos sehr ungünstigen Lebensverhältnissen in ausreichende, regelmässige Ernährung und zugleich geringere Arbeitsleistung gegen früher versetzt wurden. Seine sämmtlichen Untersuchungen waren an Anstaltsschwangeren vorgenommen worden, deshalb wirft er die Frage auf, ob bei Hochschwangeren ausserhalb der Entbindungsanstalten auch ohne solchen Wechsel der Lebensweise in den letzten Wochen Steigerung der Hämoglobinmenge vorkommt. Eine zweite Untersuchungsreihe betraf die Zeit nach der Geburt. Hier nahm die Hämoglobinmenge des Blutes in der Mehrzahl der Fälle (47 Mal von 83) ab, in einer kleinen Anzahl (10 Fälle) blieb sie sich gleich und in weiteren 26 Fällen war eine wenn auch geringe Zunahme nach der Geburt festzustellen. $\mathrm{Zu}$ diesen letzteren gehörten wahrscheinlich solche, die schon längere Zeit vor der Geburt untersucht worden waren, bei denen dann bis zur Geburt eine Steigerung eingetreten war, die durch die Geburt nicht wieder bis zu dem früher gefundenen Werthe herabgedrückt wurde. Die stärkste Abnahme von 41 Proc. wurde bei Placenta praevia, also nach bedeutendem Blutverluste, beobachtet, wie ja von vornherein zu erwarten. Die Zählung der rothen Blutkörperchen ergab Mengen von 3-4 Millionen pro $1 \mathrm{cmm}$ (Minimum 2330000 , Maximum 4750000), Zahlen, welche weit hinter den von Ingerslev aufgestellten Mittelwerthen für Schwangere und Nichtschwangere zurückbleiben. In $2 / 3$ der Fälle nahm die Menge der rothen Blutkörperchen, entsprechend der Steigerung oder Abnahme der Hämoglobinmenge, zu und $a b$; so konnte namentlich nach der Geburt eine Verminderung ihrer Zahl festgestellt werden. In $1 / 3$ der Fälle war die $\mathrm{Zu}$ - und Abnahme nicht übereinstimmend mit der des Hämoglobins, doch waren in diesen Fällen die Schwankungen meist sehr unbedeutend.

Dies die Ergebnisse der Untersuchungen Fehling's, soweit sie das Blut der Schwangeren und Wöchnerinnen betreffen. Es wurde somit zum ersten Male für den Menschen das bestätigt, was schon Spiegelberg und Gscheidlen aus Thierversuchen abgeleitet hatten, und jedenfalls konnte schon jetzt so viel be- 
hauptet werden, dass ein chloro-anämischer Zustand des Blutes der Schwangerschaft nicht eigenthümlich sei. Nachdem einmal eine neue Bahn zur Entscheidung der wichtigen Frage, ob und in welcher Weise das Blut an den bedeutenden Veränderungen sich betheilige, welche der gesammte weibliche Organismus während der Schwangerschaft erleidet, eröffnet war, wurde an der Erledigung dieser Fragen auch von anderer Seite gearbeitet, und durfte man hoffen, dass man zu einem endgültigen Abschlusse gelangen würde, wenn Fehling's Ergebnisse Bestätigung fanden. Zunächst begann J. Meyer seine Arbeiten an dem Materiale der Entbindungsanstalt in Bern. Auch er bediente sich des Apparates von Fleischl, wie er auch zugleich mit den Hämoglobinbestimmungen Blutkörperchenzählungen vornahm. Er stellte aus 10 Untersuchungen an nichtschwangeren, gesunden Frauen einen Mittelwerth 、 für Hämoglobin und rothe Blutkörperchen fest, mit welchem ex dann die aus den Untersuchungen an Schwangeren berechneten verglich. Es ergab sich ihm für Nichtschwangere ein Mittel von 85,4 Proc. Hämoglobin und 5,90 Millionen Blutkörperchen. Seine weiteren Untersuchungen erstreckten sich auf 37 Schwangere, in der Mehrzahl Frauen vom Lande, ,die meist ein gutes Aussehen und einen befriedigenden Ernährungszustand zeigten“. Jede Frau wurde drei Mal untersucht: zuerst bei ihrem Eintritte in die Anstalt, dann in den ersten Tagen nach der Geburt und endlich bei ihrem Austritte aus der Anstalt, am Schlusse des Wochenbettes, d. h. am 11. oder 12. Tage nach der Geburt.

Sehr auffällig und von denen Fehling's recht abweichend sind nun seine Ergebnisse. Er stellte fest:

1) Im Blute von schwangeren Frauen, die sich in den letzten Monaten befinden, ist die Menge der rothen Blutkörperchen und des Hämoglobins vermindert, und zwar beträgt diese Verminderung zu Anfang des letzten Schwangerschaftsmonates 0,70 Millionen Blutkörperchen auf $1 \mathrm{cmm}$ Blut and 7,8 Proc. Hämoglobin im Mittel. Die Werthe für die Menge der Blutkörperchen schwanken zwischen 3,56 bis 6,29 Millionen und die für den Hämoglobingehalt zwischen 62-95 Proc.

2) Kurze Zeit nach der Geburt findet man die Anzahl der rothen Blutkörperchen und die Menge des Hämoglobins im Blute der Neuentbundenen meistens bedeutend vermindert; das arith- 
metische Gesammtmittel ergiebt folgende, auf den vierten Tag nach der Geburt fallende Werthe: 4,62 Millionen Blutkörperchen und 66,7 Proc. Hämoglobin. Also eine Abnahme der Blutkörperchenmenge um 0,58 Millionen und des Hämoglobins um 10,9 Proc. im Mittel gegenüber der Schwangerschaft. Diese Verminderung muss auf Rechnung der unter der Geburt erfolgten Blutungen gesetzt werden.

3) Nach erfolgter Geburt findet im Wochenbette wieder eine Vermehrung der rothen Blutkörperchen und des Hämoglobins statt. Diese Vermehrung war in einer Anzahl der Fälle so bedeutend, dass schon zwei Wochen nach der Geburt die betreffenden Werthe höher waren, als die bei derselben Frau in der Schwangerschaft gefundenen.

Meyer ist daher geneigt, der Ansicht jener älteren Forscher beizutreten, welche einer hydrämischen Blutbeschaffenbeit der Schwangeren das Wort reden, und glaubt, dass jene Rückbildung des Blutes zur Norm natürlich in den ersten zwei Wochen nach der Geburt noch nicht vollendet sei, sondern wie die der anderen Organe des Weibes noch eine längere Zeit in Anspruch nehme. Allerdings ist ihm der grosse Unterschied zwischen seinen Ergebnissen und denen Fehling's auch auffällig, und er scheint geneigt zu sein, jene von Fehling beiläufig geäusserte Ansicht über eine fehlerhafte Aichung der Blutpipette in dieser Hinsicht als Lrklärungsgrund anzusprechen.

Diese sich so gänzlich widersprechenden Ergebnisse veranlassten C. Reinl an der geburtshülflichen Klinik in Prag, denselben Gegenstand einer Prüfung zu unterziehen. Gegen Fehling machte er hauptsächlich geltend, dass ein so bedeutender Hämoglobingehalt des Blutes bei einer gleichzeitig verhältnissmässig sehr geringen Anzahl der rothen Blutkörperchen nur unter ganz bestimmten pathologischen Verhältnissen vorkomme, während er andererseits gegen die Meyer'sche Arbeit verschiedene Einwände erhebt, deren einem ich vollkommen zustimmen kann. Dass er den grossen Altersunterschied der von Meyer untersuchten Schwangeren (von 19 bis zu 45 Jahren) betont, scheint mir unerheblich, ebenso dass er die Fälle mit Struma und Fluor albus ausgeschlossen haben will. Was die erstere betrifft, so dürfte ein gänzliches Fehlen derselben bei weiblichen Individuen im Canton Bern schwer anzutreffen sein. Das Hauptgewicht 
möchte ich jedoch mit Reinl darauf legen, dass Meyer seine Fälle während der Schwangerschaft je nur ein Mal untersucht hat, obgleich doch schon Fehling gezeigt hatte, dass man die Betreffenden innerhalb der letzten Schwangerschaftsmonate wiederholt untersuchen müsse. Hervorheben möchte ich noch, dass auch Reinl zur Erklärung der grossen Unterschiede in den Hämoglobinbestimmungen der beiden Forscher eine etwaige falsche Aichung der Maasspipetten heranzieht, da er durch mehrjährige Praxis mit dem Fleischl'schen Apparate, besonders bei Vergleichsbestimmungen, in der That feststellen konnte, dass diese Maasspipetten wenigstens manchmal falsch geaicht verkauft werden. Reinl benutzte zu seinen Hämoglobinbestimmungen die auf der quantitativen Spectralanalyse begründete Methode von Vierord $t$ und bediente sich dazu des Spectrophotometers von Glan (Wiedemann's Annalen 1877. Neue Folge. Bd. I, S. 351: Glan, „Ueber ein neues Photometer"). Mit Hülfe der von Hüfner für das Hundeblut-Hämoglobin gefundenen Constanten lassen sich die für Menschenblut gefundenen Extinctionscoëfficienten in absolute Werthe des Hämoglobingehaltes umrechnen. Ueber die Einzelheiten verweise ich auf die angezogenen Schriften. Seine Untersuchungen sind um so brauchbarer, als er sie gleichzeitig mit dem Fle ischl'schen Apparate nachprüfte, wodurch ein Vergleich mit den früheren Arbeiten ermöglicht wird. Er verfuhr ähnlich wie Meyer. Auch er stellte einen Mittelwerth aus 10 Untersuchungen an nichtschwangeren Frauen im Alter von 18-32 Jahren auf und fand für die Blutkörperchenzahl 4497300 , für den procentigen Hämoglobinwerth 12,24 Proc. und für den Hämoglobingehalt nach Fleischl 95 Proc. Dann ging ex zu der Untersuchung der auf der Prager Klinik befindlichen Schwangeren über, bestimmte bei etwa 30 den Hämoglobingehalt während der Schwangerschaft wiederholt, dann wenige Stunden nach der Geburt und endlich am 7.-8. Wochenbettstage. Er fand, dass den mit dem Hämometer bei Nichtschwangeren erhaltenen Mittelwerth von 95 Proc. Hämoglobin 24 der untersuchten Schwangeren erreichten oder überstiegen, und den von Fle is chl selbst für gesunde Frauen festgestellten Normalwerth von 93 Proc. Hämoglobin erreichten sogar 30 unter seinen 51 Fällen. Was die Anzahl der rothen Blutkörperchen betrifft, so wurde der für Nichtschwangere geltende Mittelwerth von 4797300 bei 21 untersuchten Schwangeren erreicht oder übertroffen. Für diese 21 Schwangeren wurde ein Mittel von 
314 Schroeder, Untersuchungen thber die Beschaffenheit des Blutes

5156000 Biutkörperchen in $1 \mathrm{cmm}$ gefunden. Jene Schwangeren, deren Hämoglobingehalt ein höherer war, als der für Nichtschwangere ermittelte, hatten bis zu ihrer Aufnahme in die Gebäranstalt unter recht günstigen Ernährungsverhältnissen gestanden, oder aber es machte sich der durch den längeren Aufenthalt in der Anstalt bedingte Einfluss einer besseren Ernährung, besonders einer reichlicheren Eiweissnahrung (Subbotin, Leichtenstern) geltend. Dieser günstige Einfluss der Anstalt zeigte sich namentlich in den Fällen, bei denen eine mehrmalige Blutuntersuchung vorgenommen werden konnte; es stiegen bei 15 Fällen die Mittelwerthe von 4098707 rothen Blutkörperchen auf $1 \mathrm{cmm}$ und 70 Proc. Hämoglobin beim Eintritte in die Anstalt auf 4871914 rothe Blutkörperchen und 94 Proc. Hämoglobin kurz vor der Geburt. Reinl schliesst daher, ,dass der Schwangerschaft kein eigentlich chloro-anämischer Zustand, bezw. kein anämisirender Einfluss qua se mit Ausserachtlassung aller socialen und individuellen Verhältnisse zugeschrieben werden darf." Tritt eine Verschlechterung der Blutbeschaffenheit bei Schwangeren ein, so sollen daran die meist elenden socialen Verhältnisse der Betreffenden Schuld sein, da sich der günstige Einfluss eines Aufenthaltes in der Anstalt bei diesen ausgehungerten und abgehetzten Personen auffällig geltend gemacht habe. Vor allem aber habe er nicht jenes auffallende Verhältniss des niederen Hämoglobingehaltes und der sehr bedeutenden Anzahl von rothen Blutkörperchen, wie es von Meyer aufgestellt sei, nicht jene wahre Oligochromhämie, bestätigen können. Es habe sich bei seinen Fällen dann stets um einfache Anämie gehandelt, d. h. die Verminderung der rothen Blutkörperchen sei dem Sinken des Hämoglobingehaltes parallel gegangen. Mit der Geburt wurde unter 37 Fällen $21 \mathrm{Mal}$ der Hämoglobingehalt herabgesetzt gefunden; in 2 Fällen blieb er gleich und in 14 Fällen zeigte sich sogar eine wenn auch geringe Zunahme des Blutfarbstoffes. Von letzteren waren allerdings 6 nicht kurz vor der Geburt untersucht worden. Die Anzahl der rothen Blutkörperchen änderte sich in gleichem Sinne wie der Hämoglobingehalt. Während des Wochenbettes wurde diese Verminderung des Hämoglobins und der rothen Blutkörperchen in der Mehrzahl der Fälle wieder ausgeglichen, bei einer Anzahl sogar wurden die für die letzte Zeit vor der Geburt gefundenen Werthe bedeutend überholt. Reinl schliesst sich also im ganzen den Ergebnissen der Arbeiten Fehling's 
an. Jedenfalls geht aus seinen Untersuchungen, namentlich aus den wiederholt während der Schwangerschaft angestellten (es sind das 30 Fälle unter seinen 51) so viel hervor, dass die Blutbeschaffenheit in den meisten Fällen eine bessere wurde, und dass in den Fällen, wo eine solche Besserung ausblieb oder sogar ein Rückgang sich herausstellte, besondere pathologische Verhä]tnisse zu Grunde lagen, z. B. nervöse Dyspepsie. Allerdings lässt sich ein gewichtiges Bedenken gegen die aus den angeführten Untersuchungen abgeleiteten Schlussfolgerungen erheben. Im Grunde beweisen sie alle nichts weiter, als dass die Blutbeschaffenheit bei geregelter, ausreichender Ernährung, namentlich bei genügender Eiweisszufuhr, bei geringerer Körperarbeit eine bessere werden würde, wie von vornherein zu erwarten stand, und dass dem die Schwangerschaft an sich nicht entgegenarbeite. Alle diese Untersuchungen waren ja an solchen Personen gemacht worden, welche mit ihrem Eintritte in die Anstalt meist sehr ungünstigen Lebensbedingungen entrissen worden waren. „Absolut einwandsfreie Resultate könnte man nur dann mit Sicherheit erwarten, wenn man die Blutbeschaffenheit bei schwangeren Personen untersuchen würde, die vom Beginne bis zum normalen Ende der Schwangerschaft unter völlig gleichen äusseren 'Bedingungen gehalten werden" (Reinl). Es leuchtet ohne weiteres die Richtigkeit dieser Behauptung ein.

In dieser Hinsicht konnte deshalb die jetzt folgende Arbeit Winkelmann's in Heidelberg nichts Entscheidendes bringen. Denn auch er machte die Versuche durchweg an Anstalts-Schwangeren und unterliess es, dieselbe Schwangere bis zur Geburt mehrfach zu untersuchen, indem er freilich den Hauptnachdruck auf die Blutuntersuchung von Wöchnerinnen verlegte. Er arbeitete ebenfalls mit dem Hämometer von Fle ischl, machte jedoch nur Hämoglobinbestimmungen. Als Mittelwerth fand er für 28 Schwangere bei nur einmaliger Untersuchung 94,107 Proc. für den Hämoglobingehalt; bei 4 Untersuchungen, die or je $2 \mathrm{Mal}$ an derselben Person vornahm, stieg der Hämoglobingehalt im Durchschnitte um 7,2 Proc., 1 Mal sank er um 6 Proc. Seine Zahlen stimmen mit denen Fehling's fast überein; auch er betrachtet daher eine Chlorose während der Schwangerschaft als nicht physiologisch. Seine zweite Untersuchungsreihe bezieht sich auf den Abend gleich nach der Niederkunft. Für diesen Zeitpunkt beträgt das Mittel 98 Proc., ist also etwas höher, als das für die Archiv f. Gynäkologie. Bd. XXXIX. Hft. 2. 
Schwangerschaft gefundene, dagegen ist es um 2,3 Proc. tiefer, als das Mittel für Schwangere im zehnten Monate (100,3 Proc.). Das geringe Absinken des Hämoglobingehaltes gleich nach der Geburt erklärt sich W in kelmann theils aus der starken Schweissabsonderung während der Geburt, wodurch der Hämoglobingehalt durch Entfernung von Wasser aus dem Blute procentualisch erhöht werden müsse, theils aus der verhältnissmässig geringeren Wasserzufuhr während der Geburt, und endlich so, dass, wie überhaupt nach stärkeren Blutverlusten, das Blut zwar quantitativ verringert sei, so lange jedoch noch dieselbe Zusammensetzung aufweise, bis es durch Wasseraufnahme aus den Geweben den Verlust wieder ausgeglichen, der Qualität nach aber sich verschlechtert habe. Der dritte Abschnitt seiner Arbeit beschäftigt sich mit den Blutuntersuchungen während des Wochenbettes, und hier hat er die betreffenden Wöchnerinnen von Tag zu Tag mit seinen Messungen begleitet, für jede einzelne eine Curve aufgestellt und aus ihnen zusammen eine Curve der Mittelwerthe hergestellt. Aus der Betrachtung derselben ergiebt sich ein auffallender Wechsel im Hämoglobingehalte: am tiefsten steht derselbe am Anfange des zweiten Tages, hebt sich dann langsam, um am dritten Tage wieder etwas zu fallen; weil, wie Winkelmann meint, das Kind jetzt die vollen Anforderungen an den mütterlichen Organismus stellt. 50 Proc. der geringsten Werthe fallen auf die ersten drei Tage nach der Geburt, 7.1,43 Proc. auf die fünf ersten Tage des Wochenbettes. Winkelmann fasst die Ergebnisse seiner Arbeit in folgenden Sätzen zusammen:

1) Die Hämoglobinmenge der Schwangeren und Wöchnerinnen überschreitet das von $\mathrm{Fle}$ ischl für gesunde Frauen angegebene Mittel von 93 Proc.; die von ihm (Winkelmann) für Schwangere gefundene Zahl 97,3 Proc. uibertrifft die Fehling's (93) um 4,3 Proc., die Meyer's (77) um 20,3 Proc.

2) Die Hämoglobinwerthe nehmen zu in den letzten Monaten der Schwangerschaft, vielleicht durch den Aufenthalt in der Anstalt und die günstigeren Nahrungsverhältnisse daselbst.

3) Der Mittelwerth für Wöchnerinnen beträgt 94,8 Proc.; der Hämoglobingehalt fällt am ersten Tage im Durchschnitte um 9 Proc., steigt jedoch schon am zweiten fast auf die normale Höhe und nimmt unter täglichen Schwankungen bis ans Ende des Wochenbettes (elften Tag) zu. 
4) Die täglichen Schwankungen sind durch vermehrten oder verminderten Wassergenuss und dessen Ausscheidung zum Theile zu erklären, vielleicht auch durch die Milchabsonderung und andere ungekannte Verhältnisse beeinflusst.

Ich gehe nunmehr zu meinen eigenen Untersuchungen über; zuvor möge es mir jedoch erlaubt sein, einige Worte über die beiden Apparate anzuführen, welche ich zu meinen Hämoglobinbestimmungen verwendete. Ich bediente mich hierzu hauptsächlich des Hämometer von Fleischl (s. Medicinische Jahrbücher der k. k. Gesellschaft der Aerzte in Wien 1885) und zu Vergleichsbestimmungen des Hämoglobinometer, welches von Gowers Ende der siebziger Jahre angegeben, später durch Sahli („Zur Diagnose und Therapie anämischer Zustände." Schweizer Correspondenzblatt 1886, Nr. 20 u. 21) sehr warm empfohlen wurde. Das beiden Instrumenten zu Grunde liegende Princip ist das colorimetrische. Während man anfangs, als man die Blutuntersuchungen auf den wichtigsten Bestandtheil desselben, den Blutfarbstoff, auszudehnen begann, den Gehalt des Blutes an letzterem durch die quantitative Bestimmung des in einer gegebenen Menge Blutes enthaltenen Eisens festzustellen suchte, dann wegen der Schwierigkeiten dieser Methode den Hämoglobingehalt auf dem Wege der quantitativen Spectralanalyse auswerthete, musste man doch immer noch nach einer Vereinfachung der Hämoglobinbestimmung streben, welche es ermöglichte, dieselben nicht nur in physiologischen Instituten und wohlausgerüsteten Kliniken vorzunehmen, sondern auch dem Arzte erlaubte, dieselbe in seiner Praxis zur Sicherstellung seiner Diagnose zu verwerthen. Diesen dritten Weg betraten die verschiedenen Abänderungen der colorimetrischen Methode, welche auf dem Vergleiche einer beliebigen Blutlösung mit einer Vergleichsfarbe beruht. In dem Apparate von Fleischl wird die entnommene Blutprobe mit einer Wassermenge verglichen, die durch ein keilförmiges Rubinglas betrachtet wird. Der Gehalt an Hämoglobin wird an einer empirisch festgestellten Scala abgelesen. Die Untersuchung darf nur bei Kerzenoder Gaslicht vorgenommen werden, indem die violetten Strahlen aus dem weissen Licht, welches zur Durchleuchtung beider Substanzen verwendet werden soll, von vornherein ausgeschieden werden müssen. Alles Nähere über diesen Apparat siehe a. a. O. Ein grosser Vorzug des Instrumentes besteht darin, dass wir nur 
kleinster Mengen Blutes zu unseren Untersuchungen bedürfen, so dass wir dieselben beliebig oft von einer und derselben Person entnehmen können, ohne hierdurch allein die Blutbeschaffenheit in unberechenbarer Weise zu beeinflussen. Auch das möchte ich hervorheben, dass das Auge nach verhältnissmässig kurzer Zeit eine grosse Uebung im Abschätzen auch geringer Helligkeitsunterschiede sich aneignet, so dass die in Rechnung zu ziehenden Fehlergrenzen kaum mebr wie 5 Proc. betragen dürften. Es waren zwei Vergleichströge beschafft worden, so dass ich bei jeder Untersuchung zwei Blutproben entnahm und die jedesmaligen Ergebnisse mit einander verglich, wie übrigens vorher schon Fehling selbst und Meyer gethan hatten. Das Princip des Apparates von Gowers ist das gleiche. In dem einen zugeschmolzenen Glasröhrchen befindet sich eine Lösung von Pikrocarmin in Glycerin, welche der Farbe einer 1 proc. Blutlösung gleichkommt. In ein zweites offenes Glasröhrchen, welches eine Scala trägt, deren einzelne Theilstriche zwischen sich ein Volumen von $20 \mathrm{cmm}$ fassen, wird die zu untersuchende Blutmenge geblasen. Diese beträgt ebenfalls $20 \mathrm{cmm}$. Es gelang mir stets durch einen einfachen Stich mit einer stärkeren Stecknadel ohne Druck so viel Blut aus der kleinen Stichwunde am Finger zu entleeren, dass ich die Pipette bis zu dem angemerkten Strich $(20 \mathrm{cmm})$ füllen konnte. Die Verdünnung geschieht mit gewöhnlichem Wasser (während ich bei dem Apparate von Fleischl vortheilhafter destillirtes Wasser verwandte), und an der Scala lässt sich dann ohne weiteres der relative Gehalt des Blutes an Hämoglobin ablesen. Ich habe in der bei weitem grösseren Anzahl meiner Fälle die Untersuchungen mit beiden Instrumenten angestellt, wobei sich nicht grössere Unterschiede ergaben, als man innerhalb der unvermeidlichen Fehlergrenzen zu erwarten hatte. Ich verzichte jedoch darauf, um meine Tabelle nicht zu sehr zu compliciren, auch die mit dem Gowers 'schen Apparate erzielten Ergebnisse anzuführen, zumal ich mich bei meinen Schlussfolgerungen doch nur auf die nach Fleischl festgestellten Hämoglobinbestimmungen beziehen werde. Es ist selbstverständlich, dass ich mich bei meinen Untersuchungen bemühte, mit möglichster Genauigkeit den Vorschriften nachzukommen, welche Fleischl selbst für das Arbeiten mit seinem Instrumente angiebt, und ich kann ihm unbedingt beipflichten, ,dass die Stimme des Gewissens, welche bei Hämometermessungen wegen ihrer grossen Einfachheit eine sehr vernehm- 
liche ist, den Beobachter in jedem einzelnen Falle über das Maass von Vertrauen unterrichtet, dessen er sich und seine Beobachtung werth gemacht hat."

Zur Zählung der rothen Blutkörperchen wurde der Mélangeur von Thoma-Zeiss verwandt, verbunden mit Zählkammer nach Gowers. Als Zusatzflüssigkeit bediente ich mich der gewöhnlichen physiologischen Kochsalzlösung, welche mir die rothen Blutkörperchen ausreichend in ihrer Gestalt bewahrte, so dass ich nicht das Bedürfniss nach anderen so zahlreich angegebenen (Malassez, Löwit u. A.) Zählflüssigkeiten empfand. Ich zählte jedesmal zwei Tropfen durch, in nicht seltenen Fällen, wenn ich irgendwie Zweifel an der Genauigkeit hegte, auch drei oder vier Tropfen, werde jedoch ebenfalls nur die aus den verschiedenen Zählungen sich ergebenden Mittelzahlen in der folgenden Tabelle anführen.

Ich unternahm diese Blutuntersuchungen hauptsächlich in dem Sinne, dass ich feststellen sollte, ob bei Hochschwangeren ausserhalb der Entbindungsanstalten auch ohne solchen Wechsel in der Lebensweise, wie er durch den Eintritt in die geordneten Verhältnisse einer Anstalt für die meisten der Schwangeren bedingt wird, in den letzten Wochen der Schwangerschaft eine Steigerung der Hämoglobinmenge vorkommt. Der Weg, welchen meine Untersuchungen zu gehen hatten, war mir dadurch klar vorgezeichnet. Erstlich mussten die Betreffenden während der Schwangerschaft wiederholt untersucht werden; nur so konnte man hoffen, beweiskräftige Ergebnisse über das Verhalten des Hämoglobin herauszubringen. Dann aber kam es vor allem darauf an, diese Untersuchungen nicht an Hausschwangeren anzustellen, denn für letztere war durch $\mathrm{F}$ ehling sowohl, wie durch die Arbeiten von Reinl in überzeugender Weise dargethan worden, dass in der Mehrzahl der Fälle eine Steigerung des Hämoglobinwerthes zu beobachten sei. Vielmehr mussten vorzugsweise solche Personen verwandt werden, welche von Anfang bis zum normalen Ende der Schwangerschaft unter denselben äusseren Lebensbedingungen standen, um behaupten zu können, dass ich die Blutbeschaffenheit der völlig physiologischen Schwangerschaft verfolgt habe. Hierzu standen mir nun in Basel zwei Gruppen von Personen zur Verfügung: Einmal solche, welche für je einen Tag in der Woche für die Touchirübungen in das Spital bestellt wurden. 
für welche Leistung sie später für die Zeit ihres Wochenbettes freien Aufenthalt im Spitale erhalten. Es ist klar, dass diese Klasse, in der Mehrzahl wohl ledig, Dienstmädchen, Fabrikarbeiterinnen, in der letzten Zeit ihrer Schwangersehaft, in welcher ihr Zustand ihnen nicht mehr erlaubt, ihre tägliche Arbeit zu verrichten, draussen meist in den elendesten Verhältnissen leben, bei völlig unzureichender Ernährung sich mühsam bis zu ihrer Niederkunft durchschlagen. Ein Theil von ihnen findet dann schon einige Wochen vor der Entbindung Schutz und Unterkommen im Spitale. Zu der zweiten Klasse gehören verhältnissmässig günstiger gestellte Personen. Es ist in Basel Sitte, dass die verheiratheten Frauen der unteren Klassen, auch wenn sie sich im übrigen durchaus nicht in schlechten Verhältnissen befinden, sehr häufig ihre Entbindung und Wochenbett im Spitale gegen eine geringe Bezahlung durchmachen. Es sind dies Frauen von kleinen Handwerkern, Fabrikarbeiterinnen, wohl auch ledige Personen, welche Bezahlung leisten können, kurz solche, die verhältnissmässig gut leben. Diese bleiben bis zu ihrer Entbindung in der Stadt. Viele von ihnen kommen schon während der Schwangerschaft, gelegentlich, um sich von der Oberhebamme untersuchen zu lassen, und so gelang es mir, von ihnen während der Schwangerschaft eine Blutprobe zu entnehmen. Wenn diese Frauen dann im Spitale niederkamen, so wurde ich gerufen und konnte so noch während der Geburt das Blut derselben Frau zum zweiten Male untersuchen. Gar nicht selten traf es sich ferner, dass besonders Erstgebärende, aber auch Mehrgebärende, sich über die bevorstehende Niederkunft täuschten, ins Spital kamen und wieder nach Hause geschickt werden mussten. So konnte ich mehrere Male das Blut derselben Schwangeren drei Mal untersuchen, auch bei solchen, die für die Touchirübungen ins Spital bestellt wurden. Daneben benutzte ich natïrlich auch die in der Anstalt befindlichen Schwangeren; es war dies nur eine kleine Anzahl, und dadurch noch verringert, dass ich meine ersten sechs Untersuchungen von Anstaltsschwangeren nicht mit in meine Tabelle aufuehme, theils weil ich nicht von der Zuverlässigkeit dieser ersten Beobachtungen überzeugt bin, theils weil ich sie nur ein Mal untersuchen konnte, und endlich aus einem Grunde, den ich sofort anführen werde. Herr Prof. Fehling hatte mir für meine Arbeiten seine eigenen Instrumente überlassen, dieselben, mit denen seine Untersuchungen angestellt worden waren. Ich bediente mich 
daher auch derselben automatischen Blutpipetten, welche Fehling selbst für vielleicht falsch geaicht hielt. Auch ich fand mit diesen Pipetten sehr hohe Werthe für den Blutfarbstoff. Auf diesen Pipetten war der Cubikinhalt nicht angegeben; nach den „Regeln für den Gebrauch des Hämometer" von v. Fleischl sollen diese Capillarröhren einen Inhalt von $6 \frac{1}{2} \mathrm{cmm}$ haben. Wir bezogen nun aus Wien eine Anzahl neuer Pipetten, deren Inhalt nach den eingepressten Zahlen $6,2 \mathrm{cmm}$ betrug. Mit diesen letzteren erhielt ich nun Werthe für das Hämoglobin, welche sich denen, die Meyer angegeben hatte, auffallend näherten; nur in 2 oder 3 Fällen wurde das Mittel von 93 Proc. erreicht. Die Fälle 1-11 meiner Tabelle sind mit den Pipetten 6,2 untersucht worden. Später wurden uns von Wien aus neue Pipetten mit 7,5 cmm Inhalt, entsprechend den vorhandenen Trögen, übersendet, mit welchen dann alle weiteren Untersuchungen vorgenommen wurden. Jetzt stiegen auch wieder die Zahlen für die Hämoglobinwerthe, wie aus der Tabelle ersichtlich ist. Ich stehe daher nicht an, die bedeutenden Unterschiede, welche sich zwischen den Arbeiten von Febling und Meyer herausstellten, in der That auf einen Unterschied in dem Inhalte der verwendeten Blutpipetten zu beziehen. Leider lassen sich die ebenso grossen Abweichungen in der Anzahl der rothen Blutkörperchen nicht in so einfacher Weise erklären, doch möchte ich auch hier vermuthen, dass wir es doch vielleicht mit Fehlern in der Untersuchungsmethode zu thun haben. Die Hämoglobinbestimmungen behalten nichtsdestoweniger, da sie mit denselben Pipetten vorgenommen wurden, einen unter sich vergleichbaren Werth, wie Fehling ausdrücklich betont.

Ich habe nun von vornherein darauf verzichtet, mir aus einer beliebigen Anzahl von gesunden, nichtschwangeren Frauen gewissermaassen einen Normalwerth herzustellen, mit welchem dann die bei Schwangeren gefundenen Hämoglobinwerthe zu vergleichen seien. Nach meiner Ansicht ist dies Verfahren unzweckmässig. Aưs den Untersuchungen eines so sorgfältigen und zuverlässigen Beobachters wie Leichtenstern geht deutlich und bestimmt hervor, dass wir gar nicht berechtigt sind, den Hämoglobingehalt des Blutes irgend eines Menschen mit dem irgend eines anderen zu vergleichen und daraus Schlüsse auf seine Beschaffenheit zu ziehen. Es sind so zahreiche Factoren, welche sich in dieser Hinsicht einflussreich erwiesen haben, wie Lebeusalter, Geschlecht, 
Körperbeschaffenheit, Ernährungszustand, selbst die verschiedenen Tageszeiten u. s. w., dass wir eigentlich immer nur das Blut einer und derselben Person, zu verschiedenen Zeiten und unter den verschiedensten Umständen untersucht, in Hinsicht auf die Veränderungen, welche seine wesentlichen Bestandtheile erlitten haben, mit einander vergleichen dürfen. Deshalb ist es so nothwendig, wenn wir zu einer Entscheidung der Frage gelangen wollen, welchen Einfluss die Schwangerschaft auf die ,Concentration des Blutes" ausübe, dass wir diese Untersuchung an derselben Schwangeren, die während der Schwangerschaft unter möglichst gleichen äusseren Bedingungen verharrt, zu wiederholten Malen vornehmen. Dann werden wir aus den Schwankungen des Hämoglobinwerthes ein treues Bild davon entwerfen dürfen, ob die Schwangerschaft an sich die Blutbeschaffenheit beeinflusst und in welcher Richtung. Ich habe dann nach dem Vorgange Fehling's und der Anderen nach der Geburt eine abermalige Untersuchung vorgenommen, meist am zweiten Tage, da nach den Curven Winkelmann's an diesem Tage der Hämoglobingehalt am niedrigsten steht, seltener schon am ersten Tage nach der Geburt und nur unter besonderen Umständen noch später. Am Schlusse des normal verlaufenden Wochenbettes wurden die Betreffenden bei ihrer Entlassung aus der Anstalt einer letzten Untersuchung unterzogen; es geschah dies meist am zwölften Tage. Nur wenn besondere Umstände, wie leichte Fieberbewegungen und dergl. hinzugetreten waren, konnte ich die Untersuchung noch mehrere Wochen nach der Entbindung ausführen. Das Hauptgewicht lege ich, wie ich hier gleich bemerken will, auf die Untersuchungen während der Schwangerschaft, da die Ergebnisse dorselben nach der Geburt von Allen übereinstimmend angegeben werden. Auch ich kann mich meinen Vorgängern hierin anschliessen.

Ich lasse jetzt meine Tabelle I folgen. F bedeutet den Hämoglobingehalt nach Fle ischl, N die Anzahl der rothen Blutkörperchen auf $1 \mathrm{cmm}$. Meine Untersuchungsreihe erstreckt sich im ganzen auf 42 Fälle. 
von Schwangeren und Wöchnerinnen u. s. w.

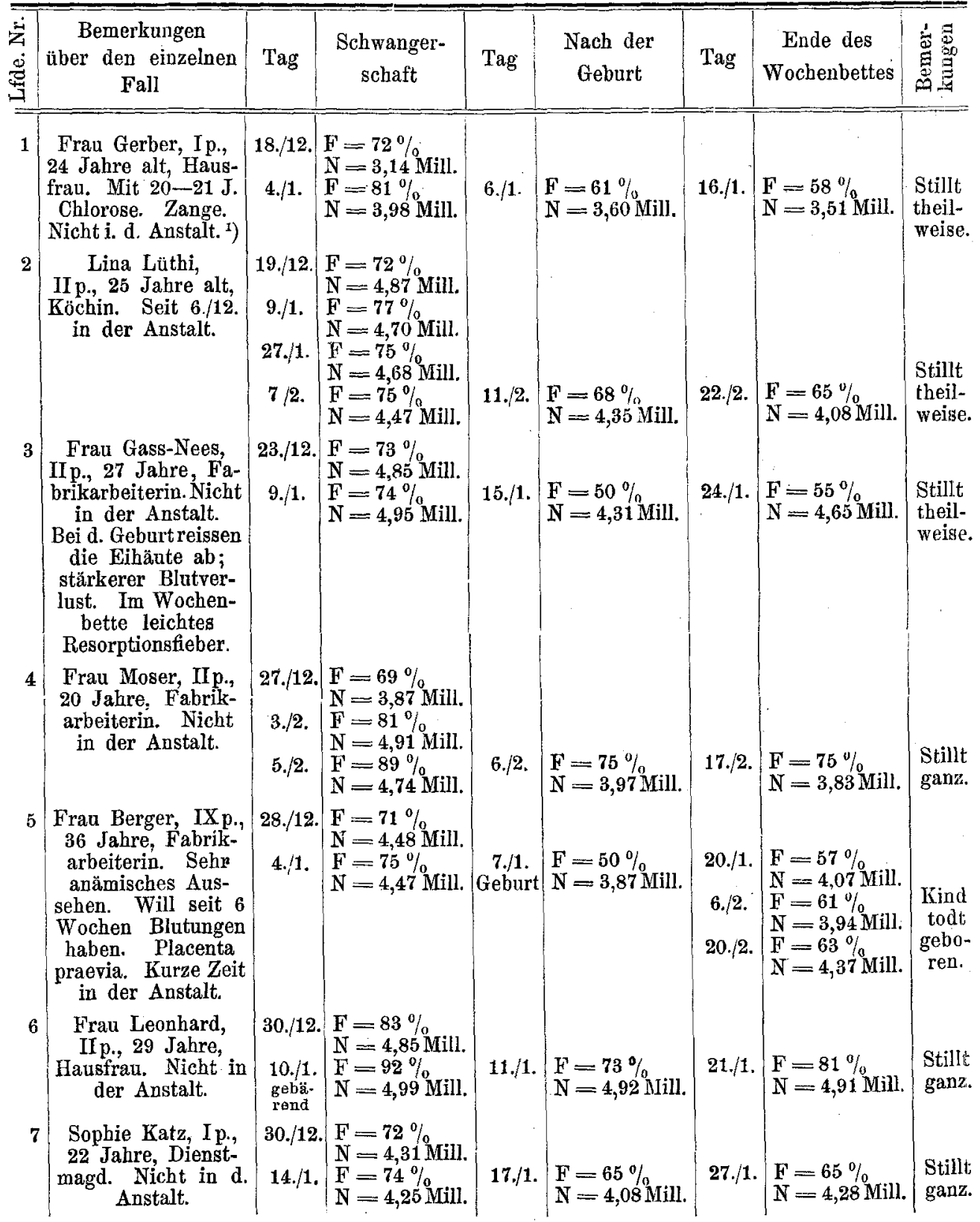

1) Die Bemerkung ,Nicht in der Anstalt" soll überall besagen, dass die Betreffende erst mit ihrer Entbindung in die Anstalt eintrat, die ganze Schwangerschaft dagegen draussen durchmachte. 
324 Schroeder, Untersuchungen über die Beschaffenheit des Blutes

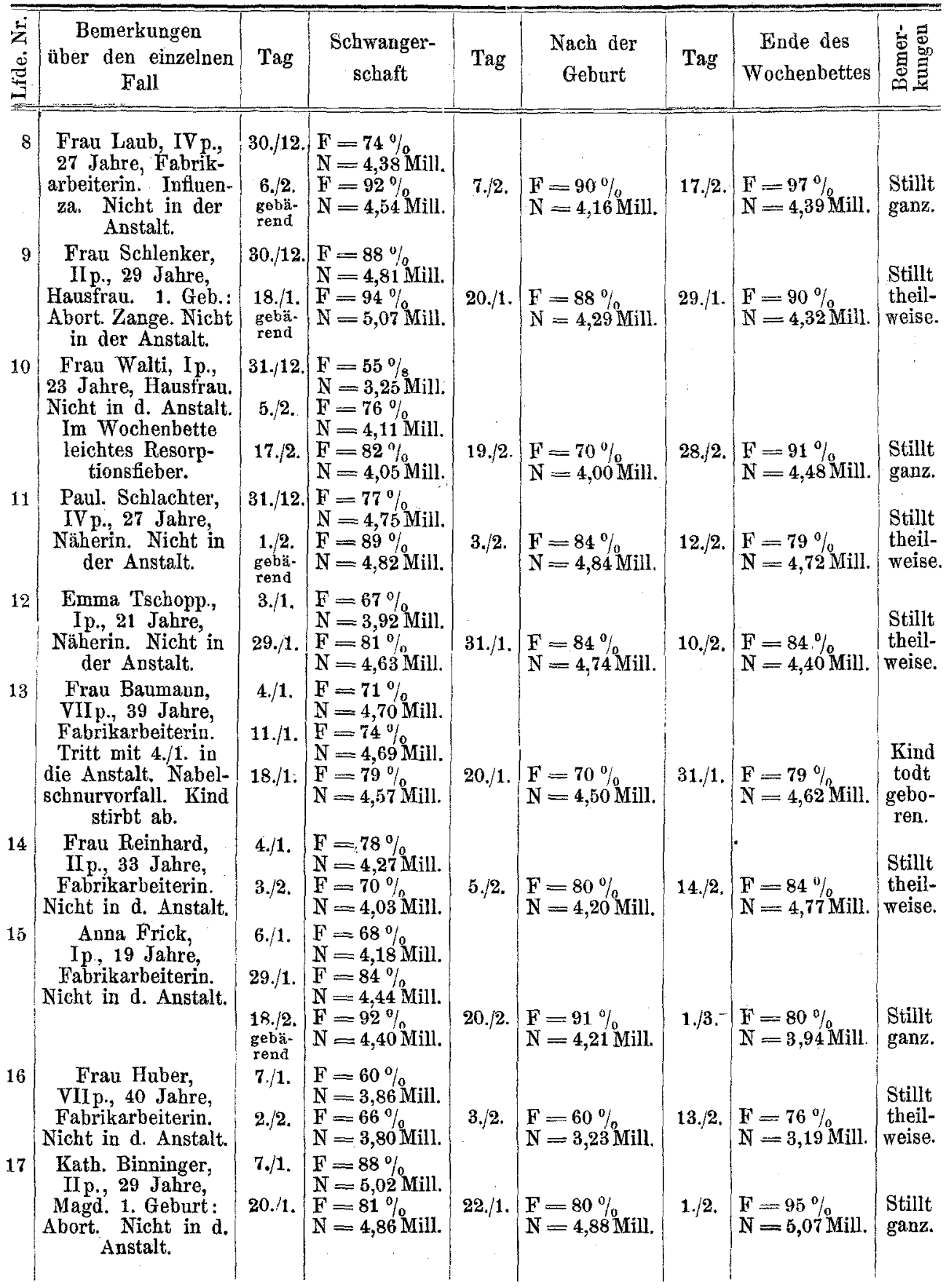


von Schwangeren und Wöchnerinnen u. s. w.

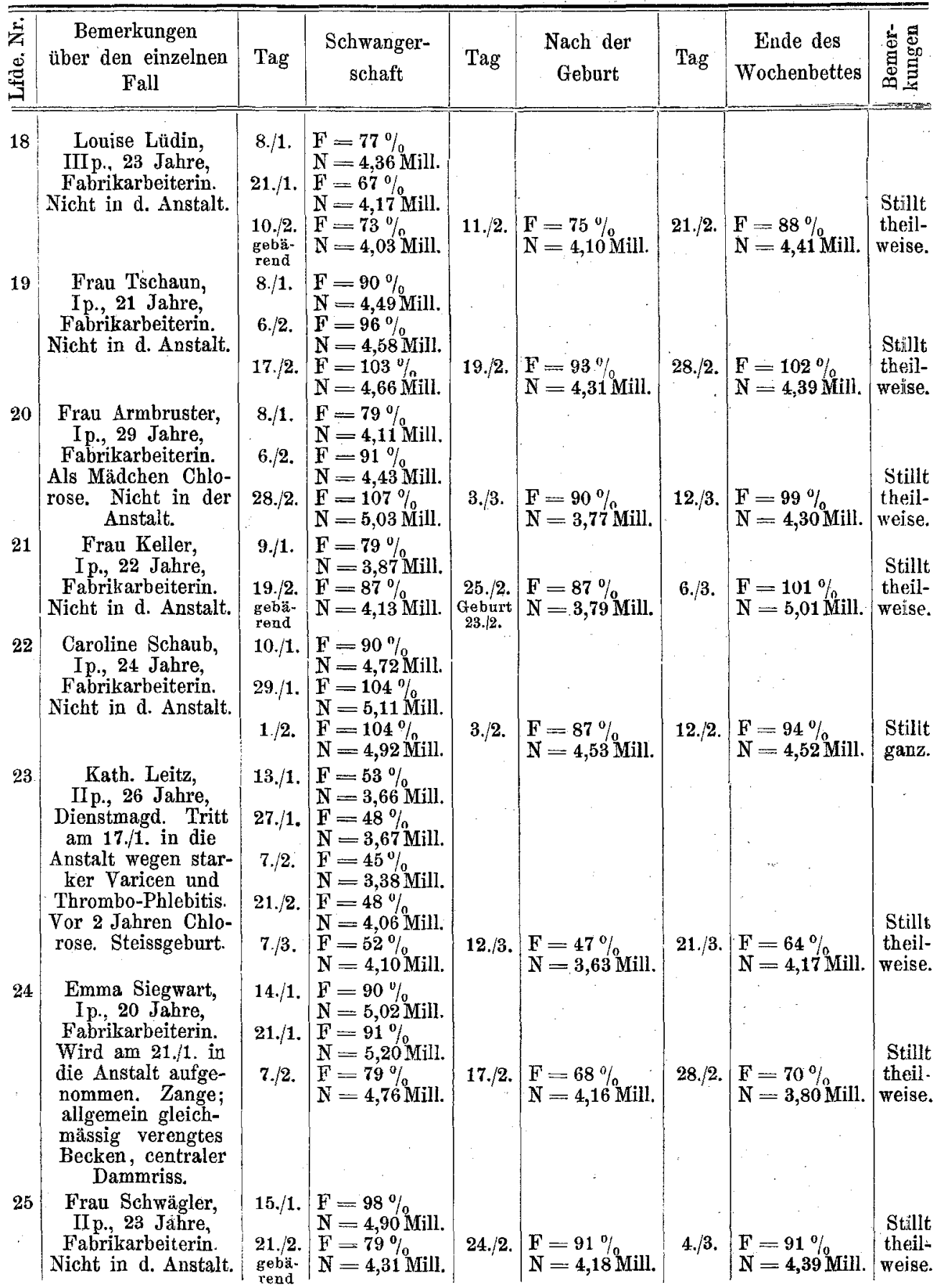


326 Schroeder, Untersuchungen über dio Beschaffenheit des Blutes

\begin{tabular}{|c|c|c|c|c|c|c|c|c|}
\hline 党 & $\begin{array}{c}\text { Bemerkungen } \\
\text { über den einzelnen } \\
\text { Fall }\end{array}$ & Tag & $\begin{array}{c}\text { Schwanger- } \\
\text { schaft }\end{array}$ & Tag & $\begin{array}{c}\text { Nach der } \\
\text { Geburt }\end{array}$ & Tag & $\begin{array}{c}\text { Ende des } \\
\text { Wochenbettes }\end{array}$ & 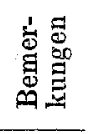 \\
\hline 26 & $\begin{array}{l}\text { Frau Ribi, } \\
\text { XVp., 40 Jahre, } \\
\text { Hausfrau. Bei der } \\
\text { Geburt starker } \\
\text { Blutverlust. Nicht } \\
\text { in der Anstalt. }\end{array}$ & $\begin{array}{l}15 . / 1 \\
28 . / 1\end{array}$ & $\begin{array}{l}\mathrm{F}=87 \% \\
\mathrm{~N}=5,47 \text { Mill. } \\
\mathrm{F}=95 \% \\
\mathrm{~N}=5,39 \text { Mill. }\end{array}$ & $29 . / 1$ & $\begin{array}{l}\mathrm{F}=70 \% \\
\mathrm{~N}=3,74 \text { Mill. }\end{array}$ & $8 . / 2$. & $\begin{array}{l}\mathrm{F}=73^{\circ} \% \\
\mathrm{~N}=3,93 \text { Mill. }\end{array}$ & $\begin{array}{l}\text { Stillt } \\
\text { ganz. }\end{array}$ \\
\hline 27 & $\begin{array}{c}\text { Kath. Bolliger, } \\
\text { Ip., } 30 \text { Jahre, } \\
\text { Fabrikarbeiterin. } \\
\text { Nicht in d. Anstalt. }\end{array}$ & $\begin{array}{l}16 . / 1 . \\
22 . / 1 \text {. }\end{array}$ & $\begin{array}{l}\mathrm{F}=70 \% \\
\mathrm{~N}=3,86 \mathrm{Mill} . \\
\mathrm{F}=71 \% \\
\mathrm{~N}=4,11 \mathrm{Mill} .\end{array}$ & $23 . / 1$. & $\begin{array}{l}\mathrm{F}=71 \% \\
\mathrm{~N}=4,00 \mathrm{Mill} .\end{array}$ & 1./2. & $\begin{array}{l}\mathrm{F}=76 \% \\
\mathrm{~N}=4,09 \mathrm{Mill}\end{array}$ & $\begin{array}{l}\text { Stillt } \\
\text { theil- } \\
\text { weise. }\end{array}$ \\
\hline 28 & $\begin{array}{l}\text { Frau Weichinger, } \\
\text { XIp., 39 Jahre, } \\
\text { Hausfrau. Influenza. } \\
\text { Seit 15./1. in d. An- } \\
\text { stalt. Im Wochenb. } \\
\text { Resorptionsfieber. }\end{array}$ & $\begin{array}{l}16 . / 1 \\
27 . / 1 \\
8 . / 2\end{array}$ & $\begin{array}{l}\mathrm{F}=94 \% \\
\mathrm{~N}=5,16 \mathrm{Mill} \\
\mathrm{F}=84 \% \\
\mathrm{~N}=4,72 \mathrm{Mill} . \\
\mathrm{F}=80 \% \\
\mathrm{~N}=4,72 \mathrm{Mill} .\end{array}$ & $13 . / 2$. & $\begin{array}{l}\mathrm{F}=67 \% \\
\mathrm{~N}=3,56 \mathrm{Mill} .\end{array}$ & 7./3. & $\begin{array}{l}\mathrm{F}=62 \% \\
\mathrm{~N}=3,53 \mathrm{Mill}\end{array}$ & $\begin{array}{l}\text { Stillt } \\
\text { theil- } \\
\text { weise. }\end{array}$ \\
\hline 29 & $\begin{array}{c}\text { Rosina Lehmann, } \\
\text { IIp. } 24 \text { Jahre, } \\
\text { Fabrikarbeiterin. } \\
\text { Nicht in d. Anstalt. }\end{array}$ & $\begin{array}{l}20 . / 1 \\
1 . / 2 .\end{array}$ & $\begin{array}{l}F=76 \% \\
N=5,18 \text { Mill } \\
F=102 \% \\
N=5,22 \text { Mill. }\end{array}$ & 3./2. & $\begin{array}{l}\mathrm{F}=100 \% \\
\mathrm{~N}=5,02 \text { Mill. }\end{array}$ & $12 . / 2$. & $\begin{array}{l}\mathrm{F}=85 \% \\
\mathrm{~N}=4,78 \mathrm{Mill} .\end{array}$ & $\begin{array}{l}\text { Stillt } \\
\text { ganz. }\end{array}$ \\
\hline 30 & $\begin{array}{c}\text { Frau Rogg, } \\
\text { IV p., 33 Jahre, } \\
\text { Fabrikarbeiterin. } \\
\text { Wird den 7./III. in } \\
\text { die Anstalt auf- } \\
\text { genommen. }\end{array}$ & $\begin{array}{l}21 . / 1 . \\
11 . / 2 . \\
4 . / 3 . \\
12 . / 3 . \\
20 . / 3 .\end{array}$ & $\begin{array}{l}\mathrm{F}=89 \% \\
\mathrm{~N}=4,38 \text { Mill. } \\
\mathrm{F}=72 \% \\
\mathrm{~N}=3,99 \text { Mill. } \\
\mathrm{F}=93 \% \\
\mathrm{~N}=4,18 \text { Mill. } \\
\mathrm{F}=74 \% \\
\mathrm{~N}=4,20 \text { Mill. } \\
\mathrm{F}=86 \% \\
\mathrm{~N}=4,47 \text { Mill. }\end{array}$ & & & & & \\
\hline 31 & $\begin{array}{c}\text { Frau Janny, } \\
\text { Vp., 30 Jahre, } \\
\text { Fabrikarbeiterin. } \\
\text { Nicht in d. Anstalt. }\end{array}$ & $\begin{array}{l}21 . / 1 \\
9 . / 2 .\end{array}$ & $\begin{array}{l}\mathrm{F}=91 \% \\
\mathrm{~N}=4,55 \mathrm{Mill} \\
\mathrm{F}=89 \% \\
\mathrm{~N}=4,48 \mathrm{Mill}\end{array}$ & $10 . / 2$ & $\begin{array}{l}\mathrm{F}=71 \% \\
\mathrm{~N}=3,35 \text { Mill. }\end{array}$ & $19 . / 2$. & $\begin{array}{l}\mathrm{F}=75 \% \\
\mathrm{~N}=4,03 \text { Mill. }\end{array}$ & $\begin{array}{l}\text { Stillt } \\
\text { theil- } \\
\text { weise. }\end{array}$ \\
\hline 32 & $\begin{array}{c}\text { Maria Dill, } \\
\text { II p., 34 Jahre, } \\
\text { Fabrikarbeiterin. } \\
\text { Im Spitale wegen } \\
\text { Influenza. }\end{array}$ & $\begin{array}{l}22 . / 1 . \\
2 . / 2 .\end{array}$ & $\begin{array}{l}\mathrm{F}=83 \% \\
\mathrm{~N}=4,48 \mathrm{Mill} \\
\mathrm{F}=86 \% \\
\mathrm{~N}=4,39 \mathrm{Mill} .\end{array}$ & $3 . / 2$. & $\begin{array}{l}\mathbf{F}=81 \% \text { mill. } \\
\mathrm{N}=4,40 \text { Mil. }\end{array}$ & $13 . / 2$. & $\begin{array}{l}\mathrm{F}=79 \% \\
\mathrm{~N}=3,79 \mathrm{Mill}\end{array}$ & $\begin{array}{l}\text { Stillt } \\
\text { theil- } \\
\text { weise. }\end{array}$ \\
\hline 33 & $\begin{array}{c}\text { Anna Müri, } \\
\text { Ip., } 22 \text { Jahre, } \\
\text { Dienstmagd. Wird } \\
\text { den } 5 . / 2 \text {. in die An- } \\
\text { stalt aufgenommen. } \\
\text { Zange. }\end{array}$ & $\begin{array}{l}28 . / 1 \\
5 . / 2 . \\
21 . / 2 .\end{array}$ & $\begin{array}{l}\mathrm{F}=89 \% \\
\mathrm{~N}=4,79 \mathrm{Mill} \\
\mathrm{F}=78 \% \\
\mathrm{~N}=4,58 \mathrm{Mill} \\
\mathrm{F}=84 \% \\
\mathrm{~N}=4,21 \text { Mill. }\end{array}$ & $25 . / 2$ & $\begin{array}{l}F=90 \% \\
\mathrm{~N}=4,76 \text { Mill. }\end{array}$ & 7./3. & $\begin{array}{l}\mathrm{F}=93 \% \\
\mathrm{~N}=4,41 \text { Mill. }\end{array}$ & $\begin{array}{l}\text { Stillt } \\
\text { theil- } \\
\text { weise. }\end{array}$ \\
\hline 34 & $\begin{array}{l}\text { Josephine Gebferdt, } \\
\text { IIp., } 20 \text { Jahre, } \\
\text { Dienstmädchen. } \\
\text { Nicht in d. Anstalt. } \\
\text { Starke Vaginitis } \\
\text { gonorrhoica. Spitze } \\
\text { Condylome. Im } \\
\text { Wochenbett Fieber. }\end{array}$ & $\begin{array}{l}28 . / 1 . \\
4 . / 3 .\end{array}$ & $\begin{array}{l}\mathrm{F}=91 \% \\
\mathrm{~N}=4,37 \text { Mill. } \\
\mathrm{F}=82 \% \\
\mathrm{~N}=3,88 \text { Mill. }\end{array}$ & $7 . / 3$ & $\begin{array}{l}\mathrm{F}=89 \% \\
\mathrm{~N}=4,17 \mathrm{Mill} .\end{array}$ & $\begin{array}{l}12 . / 3 . \\
22 . / 3 .\end{array}$ & $\begin{array}{l}\mathrm{F}=93 \% \\
\mathrm{~N}=4,52 \mathrm{Mill} \\
\mathrm{F}=104 \% \\
\mathrm{~N}=5,16 \mathrm{Mill}\end{array}$ & $\begin{array}{l}\text { Stillt } \\
\text { theil- } \\
\text { weise. }\end{array}$ \\
\hline
\end{tabular}


von Schwangeren und Wöchnerinnen u. s. w.

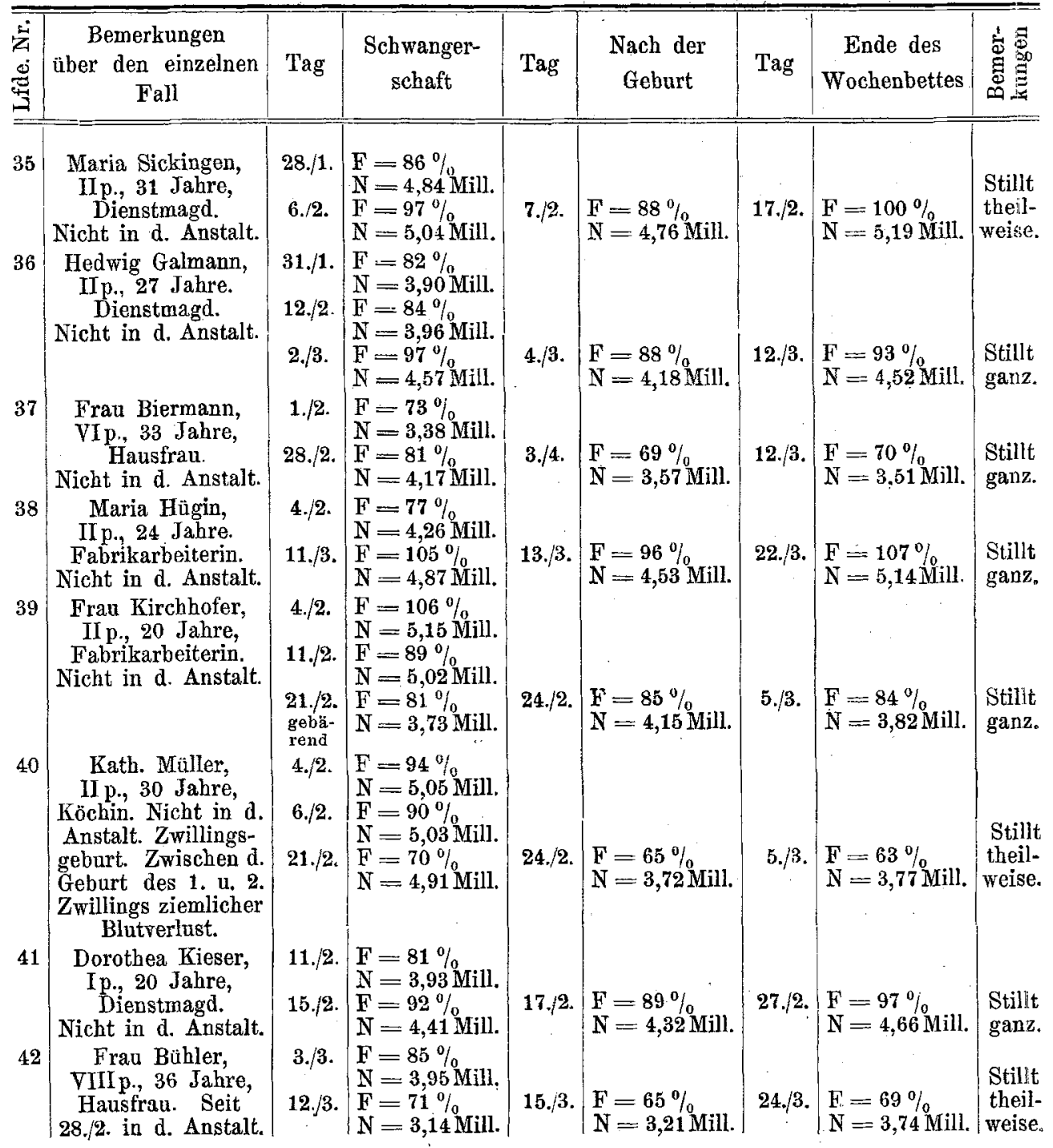

Meine Fragestellung hatte gelautet, ob sich irgend welche Unterschiede in der Blutbeschaffenheit ergeben zwischen solchen Schwangeren, welche des schützenden Aufenthaltes in einer Entbindungsanstalt theilhaftig sind, und solchen, welche ihre ganze Schwangerschaft bis zum richtigen Ende draussen unter sich gleichgleibenden äusseren Bedingungen durchmachen. Wenn ich mit - Hinsicht auf diesen Gesichtspunkt meine 42 Fälle in zwei Gruppen 
sondere, so erhalte ich allerdings nur eine beschränkte Anzahl von Hausschwangeren (Fall 2, 13, 23, 24, 28, 32, 33, 42), und wir werden sofort sehen, wie sich bei ihnen die Schwangerschaft und längerer Aufenthalt in der Anstalt in Bezug auf ihre Blutbeschaffenheit geltend gemacht haben. Nr. 2 zeigt ein geringes Steigen des Hämoglobinwerthes von 72 auf 75 Proc., Nr. 13 von 71 auf 79 Proc. Interessant ist das Verhalten von Nr. 23. Es betraf dies eine 26 jährige II para, gross, scheinbar sehr kräftig; indess ergab die Anamnese eine bis vor zwei Jahren bestehende Chlorose, und auch jetzt noch waren alle sichtbaren Schleimhäute auffallend blass. Bei dieser Person konnte selbst ein sehr langer Anstaltsaufenthalt kein Steigen des Hämoglobingehaltes bewirken. Letzterer schwankte regellos zwischen 53, 48, 45, 48, 52 Proc., fiel nach der Geburt, um dies gleich hier vorweg zu bemerken, auf 47 Proc., um dann zehn Tage später, am Ende des Wochenbettes, auf 64 Proc. zu steigen. Es wäre von Interesse gewesen, die Person noch längere Zeit nach der Geburt zu untersuchen, was leider nicht möglich war; es hätte sich auf diese Weise vielleicht feststellen lassen, ob bei diesem sicher auch jetzt noch chlorotischen Mädchen es die Schwangerschaft an sich gewesen war, welche dem sonst so günstig wirkenden Anstaltsaufenthalte entgegengearbeitet hatte. Auch Nr. 24 zeigt ein Fallen des Hämoglobinwerthes von 90 auf 79 Proc., ebenso Nr. 28 von 94 auf 80 Proc., während Nr. 32 von 83 auf 86 Proc. steigt. Dieser Fall ist jedoch nicht rein, da die Betreffende wegen Influenza 14 Tage lang im Spitale lag und es sich somit gänzlich der Berechnung entzieht, wieweit die Krankheit hier hemmend eingewirkt hatte. Belehrend ist auch Nr. 33; als sie sich zuerst im Spitale meldete, betrug ihr Hämoglobingehalt 89 Proc.; sie wurde damals noch nicht aufgenommen und war acht Tage hindurch fast obdachlos; bei sehr strenger Kälte batte sie die Nächte mehrmals im Freien in einem Schuppen zugebracht. Es war ein kräftiges 22 jähriges Mädchen. Nach acht Tagen war $F=78$ Proc. und stieg nun, da sie jetzt Aufnahme im Spitale fand, hier auf 84 Proc. Fassen wir die Ergebnisse dieser 8 Fälle zusammen, so finden wir in 3 derselben eine geringe Zunahme des Hämoglobins, in $\mathbf{3}$ anderen ein ziemlich bedeutendes Sinken desselben, während wir Nr. 23 und 32 als durch Chlorose bezw. Influenza verwickelt nicht mit in Rechnung ziehen. Was die rothen Blutkörperchen betrifft, so möchte ich zuerst bemerken, dass ich ebenso wie die früheren Untersucher ein mit dem Steigen und Fallen des Hämoglobinwerthes im allgemeinen 
übereinstimmendes Verhalten derselben beobachten konnte; allerdings kamen auch Abweichungen hierron vor, die jedoch im ganzen selten und meist nicht bedeutend waren. Für meine acht Hausschwangeren war das Verhalten der rothen Blutkörperchen folgendes: In Nr. 2 ein Fallen von 4,87 auf 4,47 Millionen, in Nr. 13 von 4,70 auf 4,57 Millionen, in Nr. 23 ein Steigen von 3,66 auf 4,10 Millionen, in Nr. 24 ein Sinken von 5,02 auf 4,76 Millionen, in Nr. 28 ein Sinken von 5,16 auf 4,72 Millionen, in Nr. 32 von 4,48 auf 4,39 Millionen, in Nr. 33 von 4,79 auf 4,21 Millionen, in Nr. 42 von 3,95 auf 3,14 Millionen. Wir haben also, einen einzigen Fall ausgenommen, überall Abnahme der rothen Blutkörperchen festzustellen, zum Theile sogar beträchtliche. Meine an einer freilich sehr kleinen Anzahl von Anstaltsschwangeren angestellten Untersuchungen ergaben also ziemlich bestimmt eine Verschlechterung der Blutbeschaffenheit, so dass ich mich hierin im Widerspruche mit den früheren Untersuchern befinde. Worauf ich dieses unerwartete Ergebniss zurückführen soll, ist mir nicht klar; vielleicht dürfte jener Umstand nicht ganz ohne Bedeutung sein, dass ich während der Wintermonte (December bis März) die Versuche anstellte, während deren die Betreffenden einer ausgiebigen Bewegung im Freien mehr oder minder entbehrten. Selbstverständlich jedoch ist die Anzahl der Untersuchten viel zu gering, als dass man irgend welche Schlïsse aus dem Verhalten ihres Blutes allgemein für die Schwangerschaft ziehen dürfte.

Ihnen stehen 34 andere gegenüber, welche ihre ganze Schwangerschaft draussen durchmachten. Von diesen zeigen 25 Fälle $=$ 73,5 Proc. Steigen des Hämoglobingehaltes und nur 9 Fälle $=$ 26,5 Proc. ein Sinken. Die letzteren sind:

\begin{tabular}{|c|c|c|c|c|c|c|c|c|c|c|}
\hline & 14 & von & 178 & 10 & auf & 7 & roc., & als & um & \\
\hline & 17 & ; & 88 & ", & $"$ & 81 & $"$ & $"$ & $"$ & \\
\hline & 18 & $"$ & 77 & $"$ & 1 & 73 & $"$ & $n$ & & \\
\hline & 25 & $"$ & 98 & $"$ & $"$ & 79 & $"$ & $"$ & , 19 & \\
\hline , & 30 & $"$ & 89 & $"$ & $"$ & 86 & $"$ & $"$ & $" 3$ & \\
\hline & 31 & $n$ & 91 & $n$ & $"$ & 89 & , & ", & , & \\
\hline & 34 & $"$ & 91 & $n$ & $"$ & 82 & $"$ & $"$ & $", 9$ & 9 \\
\hline & 39 & $"$ & 106 & $"$ & $"$ & 81 & $"$ & $"$ & $" 25$ & \\
\hline & 40 & $n$ & 94 & $n$ & $"$ & 70 & $"$ & " &, 24 & \\
\hline
\end{tabular}

Im Mittel beobachten wir demnach in diesen 9 Fällen ein Sinkell des Hämoglobinwerthes um 11,22 Proc. Von ihnen sind 6 Fabrikarbeiterinnen, die fast bis zum Augenblicke ihrer Entbindung ihre Arbeit in der Fabrik fortgesetzt hatten; 4 von ihnen 
sind unverbeirathet. Nr. 40 betrifft die Zwillingsgeburt, es ist aber natürlich ganz unberechenbar, ob und in welcher Weise dieser Umstand die Blutbeschaffenheit beeinflusst haben soll.

Setzen wir den 9 Fällen mit Sinken des Hämoglobinwerthes jene 25 anderen gegenüber, in welchen sich eine Steigerung desselben ergeben hatte. Es sind:

Nr. 1 ron 72 Proc. auf 81 Proc,, also um 9 Proc.

\begin{tabular}{|c|c|c|c|c|c|c|c|c|c|c|}
\hline$"$ & 3 & " & 73 & $" 7$ & $"$ & 74 & 9 & 19 & 9 & 1 \\
\hline 9 & 5 & $"$ & 71 & $\eta$ & $"$ & 75 & 9 & 9 & $"$ & 4 \\
\hline 9 & 6 & 9 & 83 & " & $"$ & 92 & 29 & $"$ & $" 7$ & 9 \\
\hline$"$ & 7 & $"$ & 72 & 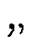 & $"$ & 74 & 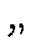 & 9 & $\eta$ & 2 \\
\hline 99 & 8 & $"$ & 74 & $"$ & $"$ & 92 & $n$ & 9 & $"$ & 18 \\
\hline 9 & 10 & $\eta$ & 55 & $n$ & 9 & 82 & $"$ & $" 3$ & $" 9$ & 27 \\
\hline 19 & 11 & 9 & 77 & $n$ & $"$ & 89 & $"$ & 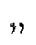 & 9 & 12 \\
\hline$"$ & 12 & $"$ & 67 & $"$ & $"$ & 81 & $n$ & $"$ & $"$ & 14 \\
\hline "I & 15 & $"$ & 68 & $n$ & $"$ & 92 & 9 & $"$ & , & 24 \\
\hline 99 & 16 & 19 & 60 & $n$ & $"$ & & $"$ & $"$ & $"$ & \\
\hline 19 & 19 & $n$ & 90 & 11 & $"$ & 103 & $"$ & $"$ & $n$ & 13 \\
\hline$"$ & 20 & 19 & 79 & $n$ & $"$ & 107 & $"$ & 9 & $"$ & 28 \\
\hline " & 21 & $"$ & 79 & $"$ & $n$ & 87 & $"$ & $"$ & $"$ & 8 \\
\hline 4 & 22 & $n$ & 90 & $"$ & $"$ & 104 & 19 & $"$ & $" 9$ & 14 \\
\hline$"$ & 4 & 19 & 69 & 9 & $"$ & 89 & $"$ & $" 1$ & 9 & 20 \\
\hline$"$ & & $" 1$ & 00 & 99 & $"$ & 34 & $"$ & $"$ & $n$ & 0 \\
\hline$"$ & 87 & $"$ & 87 & $"$ & $"$ & 95 & $"$ & 9 & $"$ & 8 \\
\hline " & $\begin{array}{l}27 \\
20\end{array}$ & $" 1$ & 70 & 19 & $"$ & 71 & 9 & $n$ & $n$ & J \\
\hline$"$ & 29 & $"$ & 76 & $n$ & $"$ & 102 & $n$ & $n$ & $n$ & 26 \\
\hline "I & 35 & $"$ & 86 & $"$ & $"$ & 97 & 19 & 19 & 19 & 11 \\
\hline$"$ & 36 & $n$ & 82 & $" y$ & $"$ & 97 & 9 & $"$ & $n$ & 15 \\
\hline$"$ & 37 & $"$ & $\begin{array}{l}73 \\
77\end{array}$ & $"$ & $"$ & 81 & ," & $"$ & 9 & 8 \\
\hline$"$ & 38 & $"$ & 77 & $"$ & $"$ & 105 & $"$ & $"$ & $"$ & 28 \\
\hline 19 & 41 & $"$ & 81 & $"$ & $"$ & 92 & , & $" 9$ & 9 & 11 \\
\hline
\end{tabular}

In diesen 25 Fällen also im Mittel ein Steigen des Hämoglobinwerthes um 12,92 Proc.; unter ihnen finden sich 11 Unverheirathete, meist kräftige, jüngere Mädchen; unter den 14 Verheiratheten sind 6 , welche ihr Hauswesen selber besorgen und dabeim arbeiten, die übrigen sind Fabrikarbeiterinnen.

Nach diesen Ergebnissen, soviel man aus dem immerhin recht kleinen Materiale zu schliessen berechtigt ist, möchte ich mich der Ansicht Fehling's anschliessen, dass wir in der Schwangerschaft kein die Blutbeschaffenheit in ungünstigem Sinne abänderndes Moment zu erblicken haben. Es ist ja allerdings von vornherein einleuchtend, dass zur endgültigen Entscheidung eine viel grössere Anzahl von Untersuchungen erforderlich ist, dass man 
diese Jahre lang fortsetzen müsste, bis man über hinreichend grosse Zahlen verfügte. Indess geht doch aus den nunmehr von drei Seiten (Fehling, Reinl und mir) gewonnenen Ergebnissen soviel schon jetzt hervor, dass diejenigen, welche der Schwangerschaft eine hydrämische Blutbeschaffenheit zusprechen wollen, dies bisher in keiner Weise nachgewiesen haben. Die Uebereinstimmung, wie sie zwischen den eben genannten Arbeiten besteht, kann keine zufällige sein. Ich hätte allerdings gewünscht, noch unzweideutigere Ergebnisse zu erhalten; immerhin ergiebt sich doch soviel, dass ein Steigen des Hämoglobingehaltes während der Schwangerschaft fast drei Mal so häufig vorkommt, als ein Sinken desselben.

Ich betrachte schliosslich das Verhalten der rothen Blutkörperchen und mache wieder die zwei Gruppen mit Sinken des Hämoglobin in 9 Fällen gegenüber den 25 Fällen mit Steigen desselben :

Nr. 14 von 4,27 Mill. auf 4,03 Mill., also ein Minus von 0,24 Mill.

\begin{tabular}{|c|c|c|c|c|c|c|c|c|c|c|c|c|c|}
\hline 17 & 17 & 99 & 5,02 & $"$ & 9 & 4,86 & $"$ & $"$ & $"$ & ", & $"$ & 0,16 & $"$ \\
\hline " & 18 & $\%$ & 4,36 & $n$ & $"$ & 4,03 & $n$ & $"$ & $?$ & $"$ & $"$ & 0,33 & $"$ \\
\hline & 25 & $n$ & 4,90 & $"$ & $"$ & 4,31 & $"$ & $"$ & 19 & $" 9$ & $"$ & 0,59 & $"$ \\
\hline , & 30 & 9 & 4,38 & $"$ & $"$ & 4,47 & $"$ & $M$. & $\%$ & Plus & $"$ & 0,09 & $"$ \\
\hline 7 & 31 & $"$ & 4,55 & $"$ & $"$ & 4,48 & $" 9$ & $"$ & " & Minus & $"$ & 0,07 & $" 9$ \\
\hline 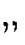 & 34 & $n$ & 4,37 & $"$ & $"$ & 3,88 & 9 & $"$ & $"$ & $"$ & $" 9$ & 0,49 & $"$ \\
\hline & 39 & 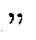 & 5,15 & 9 & $"$ & 3,73 & 9 & $"$ & $"$ & $"$ & 19 & 1,42 & 9 \\
\hline & 40 & $"$ & 5,05 & $"$ & $"$ & 4,91 & $"$ & $"$ & $"$ & 9 & $"$ & 0,14 & $"$ \\
\hline
\end{tabular}

Mit einer einzigen Ausnahme finden wir also in der That, dass sich die Anzahl der rothen Blutkörperchen entsprechend dem Sinken des Hämoglobinwerthes vermindert, und zwar im Mittel um 0,43 Millionen. In Nr. 30, wo wir ein Fallen des Hämoglobingehaltes von 89 auf 86 Proc. haben, findet sich die unbedeutende Vermehrung der rothen Blutkörperchen um 0,09 Millionen.

In der zweiten Gruppe ist das Verhalten der rothen Blutkörperchen folgendes:

Nr. 1 von 3,14 Mill, auf 3,98 Mill, also ein Plus von 0,84 Mill.

\begin{tabular}{|c|c|c|c|c|c|c|c|c|c|c|c|c|}
\hline$\eta$ & 3 & $y$ & 4,85 & $n$ & $\eta$ & 4,95 & $\eta$ & $\eta$ & $\eta$ & $n$ & $n^{\circ}$ & 0,10 \\
\hline$\eta$ & 4 & $n$ & 3,87 & $"$ & $\eta$ & 4,74 & $\eta$ & $n$ & $"$ & $n$ & $" 7$ & 0,87 \\
\hline$\eta$ & 5 & $\eta$ & 4,48 & $n$ & $"$ & 4,47 & $"$ & $"$ & $"$ & Minus & $n$ & 0,01 \\
\hline$"$ & 6 & $\eta$ & 4,85 & $n$ & $\eta$ & 4,99 & $n$ & $"$ & $"$ & Plus & $"$ & 0,14 \\
\hline$"$ & 7 & $n$ & 4,31 & $"$ & $"$ & 4,25 & $\eta$ & $"$ & $"$ & Minus & $"$ & 0,06 \\
\hline "? & 8 & $n$ & 4,38 & $n$ & 71 & 4,54 & $n$ & $\pi$ & $" n$ & Plus & $\eta$ & 0,16 \\
\hline$"$ & 9 & $"$ & 4,81 & $"$ & $"$ & 5,07 & $n$ & $"$ & $\eta$ & $" n$ & 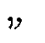 & 0,26 \\
\hline$\eta$ & 10 & $\eta$ & 3,25 & $n$ & $\%$ & 4,05 & $\%$ & 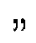 & $"$ & $"$ & $\%$ & 0,80 \\
\hline 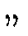 & 2 & 17 & 4,75 & $\eta$ & 9.9 & 4,82 & $"$ & $"$ & $"$ & $n$ & 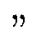 & 0,07 \\
\hline
\end{tabular}


332 Schroeder, Untersuchnngen über die Beschaffenheit des Blutes

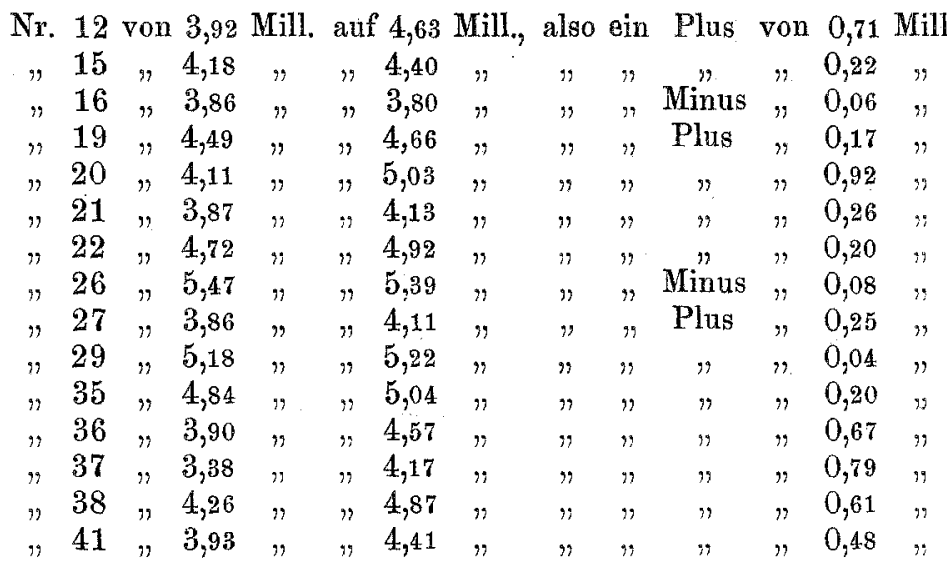

Vier Mal also unter diesen 25 Fällen sind die Aenderungen in Hämoglobingehalt und der Anzahl der rothen Blutkörperchen nicht gleichsinnig, aber wie ersichtlich, sind die Unterschiede recht mnbedeutend, 0,05 Millionen im Mittel. In allen übrigen Fällen steigt die Anzahl der rothen Blutkörperchen gleichzeitig mit dem Hämoglobingehalte im Mittel um 0,417 Millionen.

Ich wende mich nunmehr zu der zwoiten Untersuchungsreihe, welche nach der Geburt vorgenommen wurde und meist am zweiten Tage nach der Geburt. Es ist klar, dass wir hier sämmtliche Untersuchten, da sie vom Augenblicke der Geburt an unter gleichen Bedingungen stehen, wofern nicht Fieber das Wochenbett verwickelt, zusammenfassend betrachten können. In der überwiegenden Mehrzahl der Fälle, in 33 unter 42, d. h. in 78,5 Proc., ergab sich gegenüber der letzten Zeit der Schwangerschaft ein beträchtliches Sinken des Hämoglobinwerthes, und zwar im Mittel um 10,4 Proc. Auch die früheren Untersucher hatten nach der Geburt ein Herabgehen des Hämoglobingehaltes in fast allen ihrer Fälle beobachtet, und ich glaube, dass die Erklärung, welche sich Winkelmann zu geben bemüht hat, völlig ausreicht, dass wir nämlich diesen Umstand hauptsächlich auf den Blutverlust während der Geburt zu beziehen haben. Dementsprechend finde ich den grössten Unterschied (20, 24, 25 und 25 Proc.) in Nr. 1: hier wurde bei der 24jährigen I para, die ein sehr zartes Aussehen bot, wegen Wehenschwäche die Zange angelegt; in der Nachgeburtszeit atonische Blutung. In Nr. 3 finde ich wegen Abreissens der Eihäute stärkeren Blutverlust angegeben; in Nr. 5 handelte es sich um Placenta praevia; Nr. 26 betrifft die XVIpara, bei welcher gleichfalls stärkerer Blutverlust, ex atonia uteri, verzeichnet 
ist. Zunächst wird ja wohl durch die Blutung nur die Quantität. des Blutes geändert werden, dann aber bei der Wiedererzeugung werden sich zuerst die flüssigen Bestandtheile durch Aufnahme von Gewebsflüssigkeit in das Blut wieder ersetzen, wodurch der Hämoglobingehalt procentualisch sinken muss. Zur Bildung neuer rother Blutkörperchen bedarf es dagegen einer etwas längeren Zeit. In 7 meiner Fälle konnte ich eine Zunahme des Hämoglobingehaltes beobachten, im Mittel um 6,28 Proc., während er sich in 2 Fällen gleich blieb. Fehling und die Späteren, welche zum Theile Gleiches feststellten, führten dies darauf zurück, dass die Betreffenden längere Zeit vor der Geburt untersucht worden waren, dass der Hämoglobingehalt bis zur Geburt eine Steigerung erfahren haben mochte, die durch den Blutverlust während der Geburt nicht wieder ausgeglichen wurde. Wenn ich meine 7 Fälle daraufhin ansehe, so trifft dies bei keinem derselben zu: sie wurden entweder unmittelbar während der Geburt, oder nur ein bis zwei Tage vorher untersucht. Bei 5 von ihnen hatte übrigens der Hämoglobingehalt in der Schwangerschaft abgenommen. Ob dieses Zusammentreffen zufällig ist, oder ob bei diesen Frauen die Schwangerschaft in der That einen anämisirenden Einfluss ausgeübt hatte, der mit der Geburt sofort wegfiel, lasse ich dahingestellt. An sich liesse sich ja nichts dagegen einwenden, dass einzelne besonders geeignete Frauen den Anforderungen, welche die Schwangerschaft an ihren Körper stellt, nicht gewachsen wären und deshalb eine Verschlechterung ihrer Blutbeschaffenheit erleiden.

Mit dem Hämoglobingehalte nahm auch die Anzahl der rothen Blutkörperchen ab in der Mehrzahl der Fälle (32), im Mittel um 0,49 Millionen auf $1 \mathrm{cmm}$, in den 10 anderen Fällen stieg ihre Menge durchschnittlich um 0,173 Millionen, in 6 von ihnen zugleich mit dem Hämoglobingehalt, während in 4 Fällen Hämoglobingehalt und Anzahl der rothen Blutkörperchen sich in entgegengesetzter Richtung bewegten.

Die letzten Untersuchungen wurden am Ende des Wochenbettes, meist am 10.-12. Tage vorgenommen; einige der Wöchnerinnen (5), deren Wochenbett durch leichte Resorptionsfieber und dergl. verwickelt wurde, lasse ich als nicht reine Fälle hier unberïcksichtigt. Während des Wochenbettes erholt sich der weibliche Körper und kehrt, soweit möglich, zur Norm zurück. Gewiss werden wir 10-12 Tage nach der Geburt noch keine voll- 
334 Schroeder, Untersuchungen über die Beschaffenheit des Blutes

ständige Wiedererzengung des Blutes zu erwarten haben, da wir wissen, dass bis zur völligen Rückbildung der durch die Schwangerschaft beeinflussten Organe, regelmässige und günstige Wochenbettsverhältnisse vorausgesetzt, immerhin $6-8$ Wochen verstreichen. Trotzdem können wir selbst in dieser kurzen Zeit nach der Geburt einen Beginn in der Aufbesserung der Blutmischung beobachten, sofern sich diese in einem Steigen des Hämoglobingehaltes offenbart. In 25 meiner Fälle stellte ich eine Zunahme des Hämoglobinwerthes fest, um 7,64 Proc. im Mittel, während derselbe in $8 \mathrm{um} \mathrm{5,25}$ Proc. fiel und in weiteren 4 Fällen sich gleich blieb. Bei jenen 25 Wöchnerinnen war also im Mittel der Hämoglobingehalt noch um 2,76 Proc. hinter den Werthen zurückgeblieben, die er in der Schwangerschaft eingenommen hatte. Aber es lässt sich denken, dass die Neubildung von rothen Blutkörperchen und demgemäss von Blutfarbstoff noch längere Zeit fortdauern wird, so dass unter günstigen Bedingungen der durch die Geburt gesetzte Blutverlust wieder ausgeglichen ist. Leider sind jene Fälle, bei denen ich in der Lage war, eine nochmalige Untersuchung 3 bis 4. Wochen nach der Geburt vorzunehmen, nicht verwerthbar, da hier krankhafte Verhältnisse obwalteten, welche eben einen längeren Aufenthalt im Spitale nothwendig machten. In Nr. 5 z. B. (Placenta praevia), wo bei der äusserst blutarmen und schwachen Frau eine Parakolpitis während der Geburt entstanden war, ergab die Untersuchung am Tage der Geburt (7. Januar) 50 Proc. Hämoglobin, 13 Tage später 57 Proc., am 6. Februar 61 Proc., am 20. Februar 63 Proc., mithin ein sehr langsames Ansteigen. Fieber bestand nicht. Auch in Nr. 34 beobachtete ich trotz Fiebers und bestehender Schmerzen im Bauche ein Ansteigen des Hämoglobins von 89 auf 93 Proc. bis 104 Proc. Was die acht Wöchnerinnen betrifft, dereu Hämoglobingehalt um 5,25 Proc. während des Wochenbettes herabging, so sind das alles mit einer einzigen Ausnahme Fälle, bei denen sich auch schon der Geburtsvorgang in dieser Richtung geltend gemacht hatte: bei ihnen hatte also die körperliche Ruhe und die entsprechende Ernährung nicht ausgereicht, um den erlittenen Verlust wieder auszugleichen.

Um zu untersuchen, ob vielleicht die Milchabsonderung während des Wochenbettes von irgend welchem Einfluss auf das Verhalten des Hämoglobins sei, habe ich folgende Zusammenstellungen gemacht:

Von 41 Wöchnerinnen haben 2 gar nicht gestillt, da ihre Kinder bei der Geburt abstarben; bei beiden nahm der Hämo- 
globingehalt während des Wochenbettes zu, und zwar im Mittel um 11 Proc.; 15 andere Wöchnerinnen haben ihre Kinder vollständig gestillt, die Milchabsonderung war also eine ausreichende, 3 Mal, d. h. bei 13,3 Proc. blieb sich der Hämoglobingehalt gleich, $3 \mathrm{Mal}$, d. h. bei 20 Proc., nahm er ab, und zwar im Mittel um 9 Proc., $10 \mathrm{Mal}$, d. h. bei 66,6 Proc., nahm er zu, und zwar im Mittel um 8,6 Proc.; 24 Wöchnerinnen endlich konnten ihre Kinder nur theilweise stillen, neben der Brust musste noch die Flasche gereicht werden, $2 \mathrm{Mal}$, d. h. bei 8,3 Proc., blieb sich der Hämoglobingehalt gleich, $6 \mathrm{Mal}$, d. h. bei 25 Proc., nahm er ab, und zwar im Mittel um 3,3 Proc., 16 Mal nahm er zu, d. b. bei 66,6 Proc.; und zwar im Mittel um 8,8 Proc.

Will man aus diesen kleinen Zahlen einen Schluss ziehen, so kann es nur der sein, dass die Milchabsonderung von keinem Belang auf das Verhalten des Hämoglobins ist.

Etwas anders gestaltet sich dieses Mal das Verhalten der rothen Blutkörperchen. Ich finde in 22 Fällen, d. h. in 52,4 Proc., auch jetzt eine Zunahme derselben im Mittel um 0,35 Millionen, in 15 Beobachtungen jedoch, also in 47,6 Proc., eine Abnahme um 0,216 Millionen. Dürfen wir dieses immerhin befremdende Ergebniss vielleicht so deuten, dass sich das Hämoglobin schneller wieder ersetzt, als die Neubildung der rothen Blutkörperchen vor sich geht, obgleich ja im allgemeinen der eine Vorgang an den anderen gebunden und von ihm abhängig ist? Es ist ja doch von verschiedenen Forschern (Fleischl, Leichtenstern) nachgewiesen worden, dass durchaus nicht ausnahmslos ein bestimmtes Verhältniss zwischen den Schwankungen dieser beiden wichtigsten Blutbestandtheile besteht. So finde auch ich nur in 7 Fällen von den 15 Uebereinstimmung in dem Sinken des Hämoglobingehaltes und der Anzahl der rothen Blutkörperchen; in den übrigen 8 ist das Verhalten beider nicht übereinstimmend.

Wenn ich nun zum Schlusse dieses Abschnittes meiner Arbeit die Ergebnisse derselben kurz zusammenfasse, so lauten dieselben dahin, dass der Schwangerschaft kein chloro-anämischer Zustand eigenthümlich ist, dass im allgemeinen während derselben Hämoglobingehalt und Anzahl der rothen Blutkörperchen eine Steigerung erfährt, welche durch die Geburt selbst unterbrochen wird. Auf das durch die Geburt bewirkte Sinken der beiden angegebenen Blutsbestandtheile folgt im Wochenbette eine allmälige Zunahme derselben, welche voraussichtlich dann ihren Abschluss 
i̊ndet, wenn die Rückbildung des gesammten Organismus beendet ist.

Erwägen wir, dass nunmehr von drei Seiten (Fehling, Rein 1 und mir) eine Vermehrung des Hämoglobingehaltes zugleich mit der Menge der rothen Blutkörperchen nachgewiesen ist, dass dieser Nachweis geliefert wurde mit drei verschiedenen Apparaten (nach Vierordt, Fleischl, Gowers), und dass or nicht nur an Anstaltsschwangeren gelang, sondern auch an dreiviertel derjenigen, welche ihre Schwangerschaft ausserhalb des Spitales durchmachten, so, glaube ich, ist man zu dem Schlusse berechtigt, dass wir hier einer physiologischen Erscheinung, die der Schwangerschaft an sich zukommt, gegenüberstehen. Eine ausreichende Erklärung für diese Thatsachen zu geben, sind wir vorläufig wohl noch ausser Stande, indess möchte ich an jene sehr interessanten Versuche erinnern, welche B unge mit der Einäscherung ganzer neugeborener Junge und der entsprechenden Milch anstellte (vergl. „Ueber die Aufnahme des Eisens in den Organismus des Säuglings" von G. Bunge in der Zeitschrift für physiologische Chemie, Bd. XIII, Heft 5). Bunge hatte bei seinen Aschenanalysen gefunden, dass mit Ausnahme des Eisens alle anderen Bestandtheile in der Milchasche fast genau in demselben Gewichtsverhältnisse enthalten waren, wie in der Gesammtasche des Säuglings; die Eisenmenge dagegen war weit geringer, sie betrug nur den dritten Theil, bei einem wiederholten Versuche sogar nur den sechsten Theil. Diese Uebereinstimmung in den meisten Aschenbestandtheilen, welche nur durch das abweichende Verhalten des Eisengehaltes gestört wird, lässt sich teleologisch sehr gut verstehen: es waltet auch hier das so oft zu beobachtende Gesetz der Sparsamkeit vor, indem der mütterliche Organismus gerade nur soviel an den Säugling abgiebt, als dieser zum Aufbau seiner Organe braucht. Da nun aber der Eisengehalt der Milchasche sechs Mal so gering ist, als in der Gesammtasche des Säuglings, so müssten wir schliessen, dass das Neugeborene mit einer sechs Mal geringeren Menge aller Aschenbestandtheile auskommen könnte, dass hier also in der Milch ein Zuviel an den meisten organischen Bestandtheilen gegeben wird und nur das Eisen in der gerade hinreichenden Menge. Dies ist jedoch nach $\mathrm{Bung}$ e nicht der Fall, sondern wir dürfen annehmen, dass der Säugling den für das Wachsthum seiner Organe nothwendigen Eisenvorrath schon bei der Geburt in sich enthält, da wenigstens versehiedene Analysen gezeigt haben, dass der Eisengehalt des Gesammtorganismus bei der Geburt am grössten 
ist und von da ab stetig heruntergeht. Warum wird dem Fötus schon bei seiner Geburt ein so grosser Eisenvorrath mitgegeben? Bung e erklärt sich dies aus der Schwierigkeit in der Einverleibung organischer Eisenverbindungen. Würden letztere erst mit der Milch dem Säuglinge zugeführt, so würde vielleicht ein grosser Theil derselben den Darmcanal durchwandern, ohne aufgesogen zu werden, und so für Mutter und Kind verloren sein. Gelangen sie dagegen auf dem Blutwege durch die Placenta in den fötalen Körper, so sind sie vor jedem Verderben von vornherein gesichert. Deshalb wird dem kindlichen Körper schon intrauterin eine sehr grosse Eisenmenge zugeführt und deshalb ist der Eisengehalt in der Milchasche ein so sehr viel geringerer. Bunge glaubt jedoch nicht, dass diese grossen Eisenmengen während der verhältnissmässig kurzen Zeit der Schwangerschaft aus der Nahrung der Mutter einverleibt werden, sondern er nimmt an, ,dass die allmälige Aufspeicherung eines Eisenvorrathes in irgend welchen Organen der Mutter für die spätere Frucht schon längere Zeit vor der ersten Empfängniss beginnt," darum die Häufigkeit der Chlorose beim weiblichen Geschlechte und darum ihr Auftreten zur Zeit der Pubertätsentwicklung. Dem letzten Theile der Bunge'schen Theorie möchte ich nun nicht zustimmen. Ich glaube nicht, dass der weibliche Körper sich von dem Zeitpunkte an, wo er die Geschlechtsreife erlangt hat, für seine Aufgabe, der Erhaltung der Art zu dienen, in dieser Weise vorbereitet. Es wäre nicht einzusehen, warum dann z. B. nicht sämmtliche Mädchen und Frauen ausserhalb der Schwangerschaft und solange überhaupt die geschlechtlichen Thätigkeiten dauern, chlorotisch wären; wir hätten dann in der Chlorose einen physiologischen Zustand zu erblicken, der dem Weibe im Hinblicke auf seine Aufgabe, gegebenen Falles einen kindlichen Körper aufzubauen, eigenthümlich zukommt. Ich meine vielmehr, dass wir diese Eisenaufspeicherung erst von dem Beginne einer Empfängniss vor sich gehen lassen dürfen. Wenn wir bedenken, welche bedeutenden Veränderungen die Schwangerschaft im mütterlichen Körper hervorruft, wenn wir die Hypertrophie der Gebärmutter und der iibrigen Geburtswege in so kurzer Zeit sich entwickeln sehen, dürfen wir da nicht auch eine gesteigerte Thätigkeit in den Bildungsstätten der rothen Blutkörperchen, Milz, rothes Knochenmark, annehmen und findet diese nicht vielleicht ihren Ausdruck in dem erhöhten Hämoglobingehalte des Blutes und Vermehrung der rothen Blutkörperchen? Warum sollte nicht auch die Einverlei- 
bung der organischen Eisenverbindungen während der Schwanger-schaft eine gesteigerte sein, um so die für den Aufbau des kindlichen Körpers nothwendigen überreichlichen Eisenmengen zu gewinnen? An sich steht dieser Annahme gewiss nichts im Wege. Ich möchte mir so eine Erklärung für die während der Schwangerschaft eintretende Zunahme des Hämoglobingehaltes geben, bin mir natürlich sehr wohl bewusst, dass dieselbe einer sicheren Begründung noch entbehrt.

Ich gehe nunmehr zu dem zweiten Theil meiner Arbeit über. Wie bereits oben erwähnt wurde, war Fehling: von einem ganz anderen Gesichtspunkte zu den Blutuntersuchungen bei Schwangeren geschritten. Da nach allem das Fruchtwasser als ein Transsudat aus dem mütterlichen Kreislaufe, gleichviel ob sich an der Bildung desselben hauptsächlich Nabelschnur oder Placenta oder Eihäute betheiligen, aufzufassen ist, so legte er sich die Frage vor, ob nicht irgend welche Beziehungen zwischen der Blutbeschaffenheit der Mutter und der chemischen Zusammensetzung der Amniosflüssigkeit beständen, ob z. B. die Fruchtwassermenge im umgekehrten Verhältnisse zum Hämoglobingehalte des mütterlichen Blutes stände, ob nicht Hämoglobinmenge und Eiweissgehalt des Fruchtwassers in gleichem Verhältnisse mit einander zu- oder abnehmen, ob nicht demgemäss der Eiweissgehalt des Fruchtwassers bei reifen Früchten entsprechend dem höheren Hämoglobingehalte in der letzten Zeit der Schwangerschaft ein höherer sei, als bei frühreifen Frïchten. Er bestimmte deshalb in einer grösseren Anzahl von Fällen die Menge des Fruchtwassers und liess dann eine quantitative chemische Analyse desselben in Beziehung auf Trockenrückstand, Asche und Eiweiss vornehmen. Diese Fruchtwasseranalysen wurden im chemischen Laboratorium des Polytechnikum in Stuttgart von den Herren Dr. Gantter, Kehrer und Dieterle ausgeführt, während sich an den Hämoglobinbestimmungen und Blutkörperchenzählungen die damaligen Hülfsärzte des Herrn Prof. Fehling betheiligten, die Herren Dr. Erhard und Denk.

Die Frage nach der Bedeutung des Fruchtwassers war nach der Behauptung Ahlfeld's, dass dasselbe als Nahrungsmittel der Frucht anzusehen sei, wieder eine lebhaft erörterte geworden. Schon früher hatte man sich einfach damit begnügt, jene Bedeutung desselben als Nährmittel ohne weitere Begründung und ohne sich viel um die Herkunft des Fruchtwassers zu kümmern, als der Wirklichkeit entsprechend anzunehmen. Dann kamen die Er- 
fahrungen der Pathologie: man fand Verwachsungen der einzelnen Fötustheile untereinander, Spaltbildungen am Fötuskörper, Störungen in der Fintwicklung der Gliedmaassen, besonders der Füsse, man fand amniotische Stränge und Bänder u.s.w. immer vergesellschaftet mit geringer Fruchtwassermenge. Man war genöthigt, fuir das Zustandekommen eines grossen Theiles dieser krankhaften Zustände eine Oligohydramnie als erforderlich zu betrachten, und so bildete sich allmälig die im ganzen noch jetzt herrschende Vorstellung über die rein mechanische Bedeutung des Fruchtwassers heraus, dass es nur dazu diene, den Geburtscanal für die Geburt feucht zu erhalten, die Bewegungen der Frucht im Eie zu erleichtern und der Mutter weniger fühlbar zu machen, andererseits verwundende Schädigungen, welche den Körper der Mutter träfen, in ihrer Wirkung auf den Fötus abzuschwächen, ferner die Eihöhle mitsammt der Gebärmutter in gehöriger Ausdehnung zu erhalten, schliesslich durch die gefüllte und gespannte Fruchtblase den Muttermund auf schonende Weise zu eröffnen und so die Geburt einzuleiten. Als Vertreter dieser Ansicht finden wir die bedeutendsten Namen, sowohl unter den Geburtshelfern wie unter den Physiologen. Dass nebenbei der Fötus auch von dem Fruchtwasser schlucke, ohne sich jedoch davon zu nähren, war durch den regelmässigen Befund von Wollhaaren und Epidermisschuppen im Darmcanale der Frucht sichergestellt. In neuerer Zeit ist man von verschiedenen Seiten wieder zu der ursprünglichen Annahme zurückgekehrt und hat sehr entschieden die Bedeutung des Fruchtwassers als Nahrungsmittel hervorgehoben. Wenn Preyer in seiner ,Speciellen Physiologie des Embryo“ 1885, S. 256 sagt: „Die Betheiligung des Fruchtwassers am Ernährungsprocesse des Fötus ist jetzt nicht mehr zweifelhaft. Es hat sich ergeben, dass im Normalzustande vom Fötus Fruchtwasser verschluckt, verdaut, resorbirt werden kann. Wenn auch der Albumingehalt ein geringer ist, so wird die absolute Menge des aufgenommenen Albumins durch Cumulirung sehr gross und die im Amnioswasser enthaltenen Salze, vor allem sein Wasser, müssen dem Fötus zu Gute kommen," so schliesst sich Ahlfeld dem vollkommen an und behauptet, man müsse das Fruchtwasser als Nahrungsmittel der Frucht ansehen, wenn man nachwieisen kann, dass der Fötus regelmässig und häufig schluckt, dass die Darmschleimhaut die löslichen Bestandtheile des verschluckten Fruchtwassers aufsaugt und dass endlich das Fruchtwasser nährende Bestandtheile enthält. Ersteres glaubte or aus gewissen regel- 
mässig wiederkehrenden Bewegungen, die ex durch aufgesetzte Zeichenapparate an dem Fötus beobachtete, schliessen zu dürfen und ebenso aus der gleichmässigen Vertheilung der Wollhaare und Epidermisschuppen in dem ganzen Darminhalte. Dass die löslichen Fruchtwasserbestandtheile und ebenso das Wasser im Darme aufgesogen werden können, ginge daraus hervor, dass sie sich später im Meconium nicht nachweisen lassen, und ebenso aus der viel grösseren Concentration des Meconium. Wenn Fehling die Möglichkeit einer Aufsaugung des gelösten Fruchtwassereiweisses durch die Darmschleimhaut des noch ungeborenen Kindes bezweifelt, so müssen wir diese für die zweite Hälfte der Schwangerschaft wenigstens wohl zugeben. Fand doch Langendorf im 4., 5., 6. Monate Pepsin und Labferment, das von den Magendrüsen gebildet sein musste, im Magendarmcanale der Frucht, während $\mathrm{Zwe}$ ifel allerdings im 4. Monate kein Pepsin nachzuweisen vermochte. Auch die Leber arbeitet ja schon zu einer verhältnissmässig sehr frühen Zeit, so dass immerhin das Vorhandensein zweier Verdauungssäfte als sichergestellt zu betrachten ist. Um endlich den Kernpunkt der Beweisführung, nämlich dass das Fruchtwasser Nährstoffe in genügender Menge enthalte, festzustellen, machte Ahlfeld eine ganze Reihe von Eiweissbestimmungen. "Es bildete sich überall. ein Niederschlag, der nur in einzelnen Fällen minimal, in der Mehrzahl derselben aber erheblich war." Auch v. Ott (dieses Archiv, Bd. XXVII, S. 145) schliesst sich dem an, und Lomer berichtet über einen merkwürdigen Fall, in welchem sich gar kein Fruchtwasser fand, sondern nur etwa $250 \mathrm{~g}$ einer grauen, zähen, schleimigen Masse, während die Frucht zwar vollkommen ausgetragen war und die Zeichen der Reife an sich trug, sonst aber an einer auffallenden. Ernährungsstörung litt, wie ein an Atrophie leidendes Kind aussah, wie ein Neugeborenes, dessen Stoffwechsel gestört ist, das an Nahrungsmangel gelitten. Aus dieser gleichzeitigen abweichenden Beschaffenheit des Fruchtwassers und der gehemmten Ernährung des Kindes sehliesst er, dass letztere auf erstere $\mathrm{zu}$ beziehen sei. Schliesslich stellte man auch, um diese Frage zu entscheiden, Versuche mit neugeborenen Kälbern an, und es soll gelungen sein, ein solches zwei Wochen lang mit erwärmtem Fruchtwasser am Leben zu erhalten.

Es ist hier nicht der Ort, eine Kritik aller der einzelnen Punkte zu üben; nur soviel möchte ich hervorheben, ob sich nicht viel ungezwungener das Verschlucken des Fruchtwassers durch den Fötus als ein Reflexvorgang betrachten lässt, ausgelöst durch das Eindringen von Fruchtwasser in die Mund- und Rachenhöhle 
der Frucht. Dass das einmal in den Darmcanal gelangte Fruchtwasser, soweit es aufgesaugt werden kann, auch aufgesogen wird, dem steht ja nichts im Wege, wenn wir uns nicht auf den Standpunkt Fehling's stellen. Wie weit jenem ron Lomer angeführten Falle, dem sich noch ein oder zwei ähnliche (von Dr. Claudi and Mekerttschiantz) anschliessen, Beweiskraft zukommt, lasse ich dahingestellt; es ist immerhin gewagt, aus krankhaften Verhältnissen einen Rückschluss auf gesunde zu machen, wenn der Zusammenhang zwischen Ursache und Wirkung nicht ein augenscheinlicher ist. Sollte nicht in Lomer's Falle beides, sowohl die offenbare Entwicklungs- und Ernährungsstörung der Frucht und die ganz pathologische Beschaffenheit des Fruchtwassers auf eine und dieselbe Ursache zu beziehen sein, nämlich auf ein Hinderniss im utero-placentaren Verkehre zwischen Mutter und Frucht, wodurch die Blutzufuhr zum Fötus wie zu den Eihäuten eine mangelhafte wurde? Ich will die anderen Möglichkeiten, die sich zur Erklärung darbieten, unberücksichtigt lassen und bespreche jetzt die Einwände, welche besonders von Fehling gegen Ahlfeld gemacht wurden. „Ahlfeld“, so äussert sich Fehling, ,schreibt dem Fruchtwasser einen wesentlichen Nährwerth zu, indem er darin 25-50 Volumen-Proc. Eiweiss gefunden haben will. Letztere Angabe steht aber mit den Befunden aller anderen Untersucher so in Widerspruch, dass uns der Nährwerth des. Fruchtwassers nur als sehr untergeordnet erscheinen kann." Daraufhin hat ein Schüler Ahlfeld's, Sandmeyer, die Fruchtwasser-Analysen zum Gegenstande seiner Dissertation gemacht und ich will seine Ergebnisse hier kurz anführen. Er betont zunächst, dass die Angaben AhIfeld's mit denen der anderen Forscher durchaus nicht im Widerspruche ständen, denn Ahlfeld's Angaben bezögen sich auf Volumen-Procente, die der übrigen dagegen auf Gewichtsprocente. Es muss ohne weiteres zugegeben werden, dass es nicht angeht, zwischen beiden einen Vergleich ziehen zu wollen; indess vergisst Sandmeyer, dass, wenn man von dem Fruchtwasser als einem wesentlichen Nahrungsmittel redet, man dies nur durch die Angabe der Gewichtsprocente beweisen kann, welche das Eiweiss ausmacht. Sandmeyer unternahm 16 quantitative Fruchtwasseruntersuchungen an 25, bezw. 50, $100 \mathrm{ccm}$ Fruchtwasser aus dem Ende der Schwangerschaft, bestimmte Eiweiss und Asche und fand in den 16 Analysen aschefreies Eiweiss von 0,1000 bis 0,4480 , im Mittel 0,2212 in $100 \mathrm{ccm}$. In 34 weiteren Untersuchungen wurde das Eiweiss nur nach VolumenProcenten bestimmt, wobei sich ergab: 
342 Schroeder, Untersuchungen über die Beschalfenheit des Blutes

1) deutliche Opalescenz bezw, sehr geringe Niedersehläge in 7 Fällen;

2) $10-20$ Volumen-Procent in 14 Fällen;

3) $25-30 \quad " \quad, 7$,

4) $40-50, ", " 6$,

Unter den volumenmetrischen Bestimmungen finden sich auch 4, wo er zugleich quantitativ das Eiweiss bestimmte.

Volumen-Procent.

$10-20$
2) $10-20$
3) $25-30$
4) $25-30$

Procent.

0,1574

0,1332

0,2852

0,2296

Nach diesen Ergebnissen hält er sich für berechtigt, dem Fruchtwasser den Charakter eines Nahrungsmittels einzuräumen. Ich schliesse sogleich meine Tabelle II an, welche sich auf die oben berührten Punkte beziehen wird, die für den Gang der Untersuchungen Fehling's maassgebend waren.

\begin{tabular}{|c|c|c|c|c|c|c|c|c|c|c|c|c|c|c|c|c|c|c|c|}
\hline \multirow[b]{2}{*}{ Nr. } & & \multicolumn{3}{|c|}{ Kind } & \multicolumn{5}{|c|}{ Fruchtwasser } & & \\
\hline & $M u t t$ & $\mid$ & 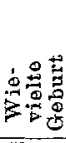 & 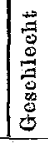 & . & 窇 & 兽 & 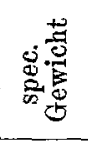 & 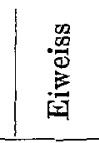 & 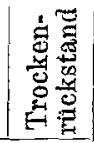 & $\begin{array}{l}0 \\
\text { 总 } \\
0 \\
0\end{array}$ & $\begin{array}{l}1 . \\
\text { y. } d .\end{array}$ & mog & $\begin{array}{c}3 . \\
\text { uat }\end{array}$ & 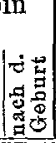 & 1. & $\begin{array}{c}2 . \\
\text { d. Get }\end{array}$ & $\begin{array}{c}3 . \\
\text { buurt }\end{array}$ & 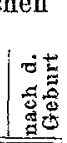 \\
\hline & & & & & $\mathrm{cm}$ & $\mathrm{g}$ & $\mathrm{g}$ & & $0_{0}$ & 0||$_{0}$ & $\left.{ }^{\circ}\right|_{0}$ & $0 !$ & $0 \mid 0$ & $\left.9\right|_{0}$ & $0_{0}$ & 12 & Mill. & Mill. & Mill \\
\hline 17 & Aml & 22 & I. & $\mathrm{K}$. & 53 & 3770 & 840 & - & 0,2084 & 0,8847 & $\mid 0,5277$ & 96 & - & & 100 & 3,24 & - & - & \\
\hline & & $|29|$ & II. & M. & 53 & 3380 & & & & & & 88 & - & - & & 3,04 & $\ldots$ & - & 3,3 \\
\hline $3 t$ & & 23 & I. & $\mathrm{K}$. & $51 \mid$ & 3320 & 200 & - & & & & 102 & - & $\ldots$ & 97 & 4,72 & - & - & 4,00 \\
\hline 26 & & 24 & II. & $\mathrm{K}$. & 50 & 3030 & 870 & 1007 & & & & 10 & - & - & 107 & 4,20 & - & -1 & 4,60 \\
\hline 82 & & 27 & III. & M. & 51 & 3500 & - & 1007 & & & & 10 & - & - & - & 3,08 & - & - & - \\
\hline 14 & & 29 & IX. & M. & 44 & 2250 & 1200 & 1006 & & & & 105 & - & -1 & 100 & 4,00 & - & - & - \\
\hline 18 & Sche & 23 & I. & M. & 49 & & 125 & - & & & & 10. & - & - & 105 & - & - & - & \\
\hline 20 & & 24 & II. & K. & $|51|$ & & 420 & $\ldots$ & & & & 110 & - & - & 110 & - & - & - & \\
\hline 40 & & 20 & I. & & 44 & 20 & wenig & - & & & & 115 & - & -1 & | 92 & 4,30 & - & - & 4,49 \\
\hline 2 & & 23 & III. & & & & & 1007 & & & & 05 & - & - & 97 & - & - & -1 & \\
\hline 46 & & 27 & III. & z. & 50 & & 1100 & 1007 & & & & 97 & - & - & 88 & 3,98 & - & - & 3,9 \\
\hline 29 & & 27 & II. & & & & wenig & & & & & 77 & & & & 356 & & & \\
\hline 54 & & & I. & & & & & & & & & & & & or & - & - & - & \\
\hline 00 & Leb & $|22|$ & I. & $\mathrm{K}$. & $\mid 51\}$ & 3690 & 600 & 1008 & & & & 106 & - & -1 & 108 & 4,02 & - & - & 4,60 \\
\hline 70 & & 20 & III. & & 9 & & viel & 1009 & & & & $67 \mid$ & - & $-i$ & 95 & -1 & - & -1 & \\
\hline 75 & & 27 & II. & & 50 & 31 & 51 & - & & & & 102 & - & - & 82 & - & - & - & - \\
\hline 102 & & 30 & III. & & & 3310 & mittel & 1008 & & & & & 110 & - & - & - & - & - & \\
\hline & & 20 & I. & & 52 & 37 & & 1005 & & & & 85 & 9 & & 100 & \begin{tabular}{ll|l}
3,88 & 4
\end{tabular} & 4,17 & - & \\
\hline 09 & Schm & 28 & I. & $\mathrm{K}$ & & 50 & & - & 0,139 & 1,1006 & & 87 & 85 & -1 & 83 & 3,77 & 2,92 & - & 3,30 \\
\hline 108 & & 19 & I. & & & 3050 & & 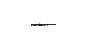 & & & & 82 & 95 & 104 & 97 & $3,22 \mid 3$ & 3,85 & 4,34 & 4,16 \\
\hline 94 & & 26 & III. & & & & $700^{\circ}$ & 1007 & & & & 108 & - & - & $105 \mid$ & -1 & - & -1 & \\
\hline & & & II. & & & & 600 & 1004 & & & & 86 & & - & 95 & & & - & \\
\hline & & 22 & II. & & & & - & - & & & & 84 & & - & 102 & 3,44 & & - & 2,87 \\
\hline & & 27 & II. & & & & mittel & 1006,5 & & & & 105 & -1 & -1 & 98 & - & - & - & \\
\hline & & 22 & $\mathbf{T}$ & & & & & & & & & & -1 & & & 4,60 & - & & 3,45 \\
\hline
\end{tabular}




\begin{tabular}{|c|c|c|c|c|c|c|c|c|c|c|c|c|c|c|c|c|c|c|c|}
\hline \multirow[b]{2}{*}{$\mathrm{Nr}}$. & \multicolumn{3}{|c|}{ Mutter } & \multicolumn{3}{|c|}{ Kind } & \multicolumn{5}{|c|}{ Fruchtwasser } & \multicolumn{4}{|c|}{ Hämoglobin } & \multicolumn{4}{|c|}{ Blutkörperchen } \\
\hline & Name & $\frac{\Phi}{ \pm}$ & 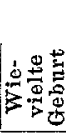 & 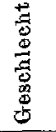 & 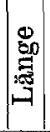 & 递 & 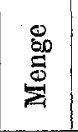 & 递 & 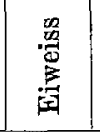 & 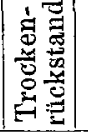 & 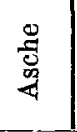 & $\begin{array}{c}1 . \\
\text { v. d }\end{array}$ & . & $\begin{array}{r}3 . \\
\text { urt }\end{array}$ & 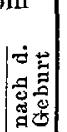 & $\begin{array}{l}1 . \\
\text { vor }\end{array}$ & \begin{tabular}{|l|}
2. \\
d. Ge
\end{tabular} & burt & \\
\hline 7 & Rieger & 22 & I. & K. & em & $\begin{array}{c}g \\
3220\end{array}$ & $\begin{array}{c}\mathrm{g} \\
\text { sehr } \\
\text { wenig }\end{array}$ & - & $\left\{\begin{array}{c} \\
0,0738\end{array}\right.$ & $\mid \begin{array}{c}{ }_{10} \\
0,996\end{array}$ & $\left|\begin{array}{c}9 \\
0 \\
0,525\end{array}\right|$ & $\left|\begin{array}{c}0 / 0 \\
90\end{array}\right|$ & $\begin{array}{l}a \\
-\end{array}$ & - & 90 & \begin{tabular}{|} 
Mi11. \\
3,62
\end{tabular} & Minl. & Mill. & \\
\hline & & 23 & I. & $\mathbf{K}$. & 50 & 3260 & $\begin{array}{r}200 \\
200\end{array}$ & 1006 & 0,153 & 0,870 & 0,543 & 105 & - & - & 80 & - & - & - & \\
\hline & & 20 & I. & $\mathrm{M}$. & 48 & 2970 & 160 & - & & & & 80 & - & -1 & $|105|$ & 3,64 & - & - & \\
\hline & & 25 & II. & $\mathrm{K}$. & 52 & 3630 & - & - & & & & 75 & - & - & 87 & - & - & - & \\
\hline & & $\mid 42\}$ & VIII & - & - & - & 2000 & 1005 & 0,167 & $|1,133|$ & 0,708 & 75 & - & - & 75 & - & - & - & \\
\hline & & 28 & I. & M. & 50 & 3330 & 400 & - & 48 & 37 & & 90 & - & - & 100 & $3,43 \mid$ & - & - & 3,01 \\
\hline & & 22 & II. & $\mathrm{K}$. & 51 & 3650 & 1800 & - & & 30 & 0,717 & 90 & 95 & - & 105 & 3,45 & 3,08 & - & \\
\hline & & 2 & I. & M. & 52 & 3480 & - & - & & 1,067 & 0,641 & 105 & 115 & -1 & 115 & -1 & - & & \\
\hline & & 17 & & $\mathbf{K}$. & 49 & 3040 & - & - & & $|1,32|$ & 0,43 & 104 & 104 & - & 115 & - & - & - & \\
\hline & & 3 & II & K & $52 \mid$ & 3120 & viel & & & & - & 96 & 98 & 95 & $|93|$ & $3,83 \mid$ & & & \\
\hline & & 20 & I. & $\mathrm{K}$. & 50 & 3350 & wenig & 1009 & & 1,29 & - & 112 & 102 & & 95 & & & & \\
\hline & & $|22|$ & I. & M. & $|49|$ & & & 1008 & & 1,06 & $\div$ & & & - & 91 & & & - & 3,56 \\
\hline & H & 22 & III. & K. & 50 & & & - & & & - & 115 & - & - & - & -1 & - & - & \\
\hline & & 2 & I & $\mathrm{K}$. & 50 & & |wenig & & & 1, & - & 95 & - & - & 93 & - & & & \\
\hline & & 2 & I & $\mathrm{K}$. & $50 \mid$ & 32 & wenis & 1008 & & 0,99 & - & 115 & - & -1 & 107 & 4,14 & - & - & \\
\hline 8 & & 2 & 1 & M. & 50 & 3800 & wenig & - & 0,0 & 1,6 & - & 115 & 120 & - & 110 & 4,18 & $|4,54|$ & - & 4,2 \\
\hline 84 & Hus & 27 & I. & & 48 & 2770 & - & 一 & 0,096 & 0,87 & - & 一 & - & - & - & - & - & - & \\
\hline 86 & Port & 24 & II. & & 42 & 1850 & wenig & - & 0,25 & 1,18 & - & - & - & - & - & 一 & - & - & - \\
\hline 85 & & - & II. & - & 52 & 3650 & viel & - & & 1,0 & - & - & - & - & - & - & - & - & \\
\hline 114 & Mor & - & - & Kodt & 31 & 700 & wenig & - & 0,695 & 1,82 & - & - & $一$ & - & - & - & - & 一 & \\
\hline 114 & Morlock & 一 & - & $\mathrm{K}$. & 28 & 700 & \begin{tabular}{|c|c|} 
sehr \\
viel
\end{tabular} & - & 0,085 & 1,13 & - & - & - & - & - & - & - & - & - \\
\hline & & & & $\mathrm{h}$ & 53 & 4200 & mittel & - & & & - & - & - & - & - & - & - & - & \\
\hline & & & & $\mathrm{K}$. & 51 & 3970 & & - & & & - & - & - & - & - & - & - & - & \\
\hline & & 24 & & M. & 49 & 3140 & viel & 一 & & 1,4 & - & - & - & - & - & - & - & - & \\
\hline & Landers & $35 \mid$ & VII & K. & 51 & 4000 & 2000 & - & 0,126 & 0,983 & - & - & -1 & $1-$ & $1-$ & - & - & - & \\
\hline
\end{tabular}

Aus diesen 50 Untersuchungen ergiebt sich ein mittlerer Eiweissgehalt des Fruchtwassers von 0,1863 Proc. gegen 0,2212 Proc. nach Sandmeyer. Ich möchte jedoch ausdrücklich hervorheben, dass ich dem von mir berechneten Mittelwerthe wegen der dreifach grösseren Menge von Untersuchungen, aus denen er gewonnen wurde, einen höheren Werth beilege. Ich habe die Untersuchungen, wie aus den Nummern erhellt, ohne Wahl zusammengestellt; berücksichtige ich nun die ersten 32 allein, so ergiebt sich für diese ein Mittelwerth von 0,2077 Proc., während für die übrigen 19 Untersuchungen das Mittel 0,1503 Proc. beträgt. Wenn wir jetzt erwägen, dass Fehling auf Grund seiner Untersuchungen für die Fruchtwassermenge $630 \mathrm{ccm}$ im Mittel angiebt (nach Gassner allerdings beträgtdie mittlere Menge gegen Ende der Schwangerschaft $1870 \mathrm{ccm}$ ), so muss die absolute Eiweissmenge in der Amniosflüssigkeit in der 
That eine kleinste genannt werden, und für die Frage, ob das Fruchtwasser eine irgendwie nennenswerthe Ernährungsquelle für den Fötus darstellt, ist ein auch noch so hoher Eiweissgehalt in Volumen-Procenten von keinem Belange. Welche Vor stellungen aber sollen wir uns dann von dem Fötus in Bezug auf das Verschlucken von Fruchtwasser bilden! Welche ungeheure Mengen von Wasser mä̈sste er in sich aufnehmen, um nur einige Gramm Eiweiss mit ihnen zu bekommen! Und wenn wir allerdings auch eine häufige Erneuerung des ganzen Fruchtwassers roraussetzen wollen, wenn wirklich auch gar kein anderer Abzugscanal für das Fruchtwasser vorhanden ist, als der Darmcanal des Fötus, wie oft und mit welcher Geschwindigkeit dieser Wechsel vor sich geht, darüber können wir vorläufig auch nicht einmal Vermuthungen aufstellen. Zudem ist durch andere Versuche erwiesen worden, dass die Eihäute in den ersten Monaten der Schwangerschaft weit weniger durchlässig sind als später; die geringe Fruchtwassermenge dieser Zeit hängt wahrscheinlich damit zusammen. Gerade für diese ersten drei Monate aber würde man noch am ehesten auf das Fruchtwasser als eine Ernährungsquelle des Fötus zurückgreifen wollen, da jetzt der Placentarkreislauf noch nicht völlig ausgebildet ist und die Ernährung des Fötus auf dem Blutwege, welche später zweifellos, wenn nicht die einzige, so đoch die bei weitem überwiegende ist, noch eine mangelhafte in dieser Art sein mag. Wäre in der That in den ersten drei Monaten der Fötus auf die Ernährung durch das Fruchtwasser angewiesen, so müssten wir eine ausserordentlich schnelle Erneuerung desselben annehmen, denn seine Menge ist sicher eine sehr geringe. Für diese Zeit aber fallen die Bedenken, die Fehling gegen die Aufsaugungsfähigkeit der fötalen Darmschleimhaut hegt, schwer ins Gewicht. Die Hauptbedeutung des Fruchtwassers möchte auch ich in seiner mechanischen Wirkung suchen; möglich ist ja immerhin, dass namentlich sein Wasser, vielleicht auch die Salze, obgleich das mütterliche Blut deren genügend für den Aufbau des Fötus mit sich führt, dem letzteren zu Gute kommen. Die Gewebe des Fötus sind sehr wasserreich und der Wassergehalt derselben nimmt bis zur Geburt freilich ab, während andererseits nach den Untersuchungen Kr üger's (,Ueber das Verhalten des fötalen Blutes im Momente der Geburt") sein Blut concentrirter, wasserärmer ist, als das der Mutter. Soviel scheint mir aus den angeführten Untersuchungen hervorzugehen, dass die Eiweisszufuhr aus dem Fruchtwasser keinesfalls eine bedeutende genannt werden 
darf und bei der Ernährung des Fötus, wenn überhaupt, nur eine höchst untergeordnete, zufällige Rolle spielt, wie im Grunde von vornherein anzunehmen ist. Es widerstrebt unserer Anschauung, dass die Natur dort, wo sie soviel einfacher ihren Zweck erreichen konnte, diesen Umweg der Durchschwitzung aus den mütterlichen Gefässen in das Fruchtwasser hinein beschreiten sollte, während derselbe Weg, auf welchem der kindliche Organismus mit $O$ versehen wird, auch für seine Ernährung offen stand.

Wenn wir nun an der Hand der Tabelle II die oben aufgestellten Fragen ins Auge fassen, so ergiebt sich in Hinsicht auf den ersten Punkt, ob zwischen der Höhe des Hämoglobingehaltes und der Menge des Fruchtwassers ein Verhältniss derart bestünde, dass das Fruchtwasser um so reichlicher vorhanden sei, je hämoglobinärmer das mütterliche Blut, dass beide von einander unabhängig $\mathrm{zu}$ sein scheinen, wie Fehling schon öfter feststellen konnte. In 38 Untersuchungen, in denen Fruchtwassermenge und Hämoglobingehalt zugleich angegeben sind, finde ich bei einer Menge von $2000 \mathrm{ccm}$ zwar den niedrigsten Hämoglobinwerth mit 75 Proc., bei $125 \mathrm{ccm} 110$ Proc. Hämoglobin, aber auch bei ,sehr wenig"، ein Mal 87 Proc. Hämoglobin und dann 90 Proc. Hämoglobin, und bei ,wenig“ 77 Proc. und bei ,viel““ 115 Proc. Hämoglobin, kurz diese in der Theorie sehr einleuchtende Annahme hat in der Praxis keine Bestätigung gefunden.

Die zweite Frage, deren Erledigung uns nunmehr beschäftigen soll, betrifft den Umstand, ob zwischen Hämoglobingehalt des Blutes und Eiweissgehalt des Fruchtwassers sich eine Beziehung in dem Sinne herausfinden lässt, dass beide gleichzeitig zu- oder abnehmen. Zu dem Zwecke stellen wir aus 42 Untersuchungen, in denen beide Bestimmungen vorgenommen wurden, die betreffenden Zahlen nach aufsteigendem Eiweissgehalte geordnet zusammen.

\begin{tabular}{cccc}
\multicolumn{2}{c}{ Eiweiss } & \multicolumn{2}{c}{ Hb-Gehalt } \\
0,03 & $\%$ & 95 & $\%$ \\
0,0437 & $n$ & 98 & \\
0,0738 & $n$ & 90 & $"$ \\
0,08 & $n$ & 120 & \\
\hline
\end{tabular}

Mittel aus 4 Un-

tersuchungen $\quad 0,0569 \% \quad 98,2 \%$

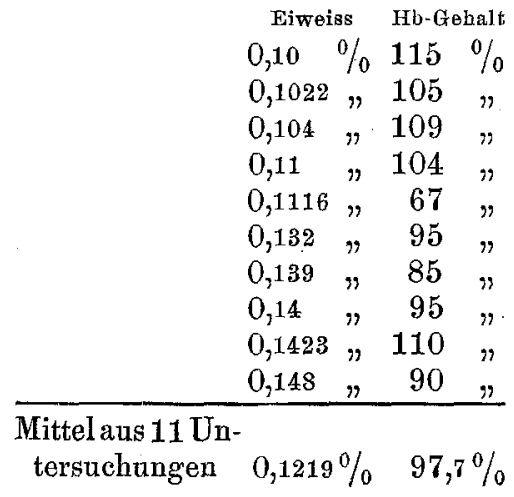


346 Schroeder, Untersuchungen thber die Beschaffenheit des Blutes

\begin{tabular}{|c|c|c|c|}
\hline \multicolumn{2}{|c|}{ Eiweiss } & \multicolumn{2}{|c|}{ Hb-Gehalt } \\
\hline 0,152 & $\%$ & 88 & $\%$ \\
\hline 0,152 & $"$ & 102 & $"$ \\
\hline 0,153 & , & 105 & 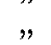 \\
\hline 0,167 & $"$ & 75 & $"$ \\
\hline 0,167 & , & 115 & $"$ \\
\hline 0,169 & ", & 84 & , \\
\hline 0,17 & , & 115 & $"$ \\
\hline 0,171 &, & 110 & $"$ \\
\hline 0,173 & $"$ & 102 & $"$ \\
\hline 0,177 & 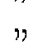 & 93 & $"$ \\
\hline 0,197 & $"$ & 102 & $"$ \\
\hline
\end{tabular}

Mittelaus 11 Un-

tersuchungen $0,168 \quad \% \quad 99,2 \%$

\begin{tabular}{|c|c|c|c|c|}
\hline & Eiweis: & & $\mathrm{Hb}-\mathrm{Ge}$ & ehalt \\
\hline & $0,2015^{\circ}$ & $\%$ & 97 & $\%$ \\
\hline & 0,2084 & $\Rightarrow$ & 96 & $"$ \\
\hline & 0,214 & $"$ & 95 & $n$ \\
\hline & 0,2180 & $"$ & 75 & $\eta$ \\
\hline & 0,229 & $"$ & 110 & $n$ \\
\hline & 0,2317 & $n$ & 115 & 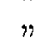 \\
\hline & 0,234 & 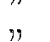 & 108 & $n$ \\
\hline & 0,24 & $n$ & 110 & " \\
\hline & 0,2463 & $"$ & 110 & , \\
\hline & 0,249 & $"$ & 105 & $"$ \\
\hline & 0,257 & $"$ & 110 & , \\
\hline & 0,266 & , & 104 &,$\eta$ \\
\hline & 0,278 & $"$ & 80 & $"$ \\
\hline $\begin{array}{l}\text { Mittel aus } 13 \mathrm{Un} \\
\text { tersuchungen }\end{array}$ & $0,2232^{0}$ & $\%$ & 101,4 & $\% \%$ \\
\hline & 0,308 & $\%$ & 106 & $\%$ \\
\hline
\end{tabular}

Wir sehen in der That eine gleichzeitige Zunahme der mittleren Werthe für den Eiweiss- und Hämoglobingehalt, wenngleich auch bei der Durchsicht der einzelnen Untersuchungen auffällt, wie gross die Abweichungen sein können, z. B.

$$
\begin{aligned}
& 0,08 \% \text { Eiweiss : } 120 \% \text { Hämoglobin und } \\
& 0,218 \% \text { : } 75 \% \text { " }
\end{aligned}
$$

Fehling hatte einen solchen Zusammenhang aus einer kleineren Zahl von Untersuchungen sichergestellt, indem er bei einem durchschnittlichen Hämoglobingehalt des Blutes

$$
\begin{array}{r}
\text { Hämoglobin Eiweiss } \\
\text { von 106,9\%: } 0,210 \% \\
\text { und von } 80 \%: 0,159 \%
\end{array}
$$

fand. Ich stelle daher die beiden Zahlenreihen noch einmal in der Weise zusammen, dass ich. die Hämoglobinwerthe unter 100 Proc. und die über 100 Proc. zusammenordne, um so mit einander vergleichbare Mittel zu erhalten. Danach sind 17 Fälle mit Hämoglobinwerthen unter 100 Proc., und zwar im Mittel mit $88,1 \%$ Hämoglobin zu einem mittleren Eiweissgehalte von $0,1532 \%$.

Ferner 24Fälle mit Hämoglobinwerthen über 100Proc., und zwar $108,2 \%$ Hämoglobin : $0,1851 \%$ Eiweiss.

Es besteht mithin wirklich eine gleichzeitige Zunahme der beiden genannten Factoren.

Dem von Fehling über den Eiweissgehalt des Fruchtwassers bei reifen und frühreifen Früchten Gesagten kann ich, was die letzteren betrifft, aus meiner Tabelle nur vier neue Fälle hinzu- 
fügen, während ich für reife Früchte die Anzahl von 35 gegenüber den 23 von Fehling erhalte. Febling hatte gefunden:

bei reifen Früchten (23) durchschnittlich 0,194\% Eiweiss,

bei frühreifen Früchten (7)

Nach meinen Berechnungen erhalte ich:

bei reifen Früchten (35) durchsehnittlich $0,1681 \%$ Eiweiss,

bei frühreifen Früchten (11)

$0,1575 \% \quad "$

Aus allem diesen geht fast mit Gewissheit hervor, dass wir das Fruchtwasser als ein seröses Transsudat aus den mütterlichen Gefässen aufzufassen haben, welches in seiner Zusammensetzung den Veränderungen folgt, die das mütterliche Blut in seinen wichtigeren Bestandtheilen erleidet. Nimmt der Hämoglobingehalt im Laufe der Schwangerschaft zu, so wächst auch die Eiweissmenge des Fruchtwassers und die Zunahme der letzteren kann um so weniger von etwa beigemengtem fötalem Harne herrühren, als dieser bekanntermaassen entweder gar kein Eiweiss oder in seltenen Fällen Spuren von Eiweiss enthält. Die Ansicht derjenigen, wonach dem von dem Fötus in die Amnioshöhle entleerten Harne ein sehr wesentlicher Antheil an der Erzeugung des Fruchtwassers zukommt, entbehrt vorläufig eines gesicherten Anhaltes Wieviel Harn der Fötus entleert, das entzieht sich jetzt noch jeder Berechnung, indess müsste man doch wohl annehmen, dass er gegen Ende der Schwangerschaft mehr entleert. Durch reichlichere Beimengung von fötalem Harne müsste demnach der Eiweissgehalt im Fruchtwasser von reifen Früchten procentualisch sinken, was, wie wir oben gezeigt haben, nicht der Fall ist. Ich befinde mich hier auch in Uebereinstimmung mit Döderlein (,Vergleichende Untersuchungen über Fruchtwasser und fötalen Stoffwechsel" in diesem Archive, Bd. XXXVII, Heft 1), dessen Tabelle VII ebenfalls eine Zunahme des Gesammtstickstoffes, sowie des Eiweissgehaltes für das Amnioswasser der Rinder-Föten in der zweiten Hälfte der Trächtigkeit beweist.

Es bleibt mir jetzt nur noch ein Punkt kurz zu erörtern übrig, wie sich die Menge des Trockenrückstandes im Fruchtwasser zu der Eiweissmenge verhält. Felling hatte aus 30 Untersuchungen gefunden, dass beide in einem bestimmten Verhältnisse zu einander stehen und giebt darüber folgende Zahlen:

Trockenrückstand in Proc.

$$
\begin{aligned}
& 1,2-1,45 \\
& 1,10-1,19 \\
& 1,0-1,056 \\
& 0,39-0,99
\end{aligned}
$$

Archiv f. Gynäkologie. Bd. XXXIX. Hft. .
Eiweiss in Proc.

$$
\begin{aligned}
& 0,278 \\
& 0,208 \\
& 0,157 \\
& 0,120
\end{aligned}
$$


348 Schroeder, Untersuchungen über die Beschaffenheit des Bhtes

Ich stelle im ganzen 47 Untersuchungen mit folgenden Er-m gebnissen zusammen:

I) bei einem Trockenrückstande unter 1,0 ein mittlerer Eiweissgehalt von $0,1239 \%$,

II) bei einem Trockenrückstande bis 1,199 ein mittlerer Eiweissgehalt von $0,158 \%$ :

III) bei einem Trockenrückstande von 1,20 ab ein mittlerer Eiweissgehalt von $0,2545 \%$.

Das von Fehling aufgestellte Gesetz erfährt also durch meine aus einer grösseren Anzahl von Untersuchungen berechneten Mittelwerthe vollste Bestätigung.

Die Frage nach der Herkunft des Eiweisses im Fruchtwasser war und ist eine noch viel umstrittene, und ihre Entscheidung ist, wenigstens für den menschlichen Fötus, um so schwieriger, als hier weit verwickeltere Verhältnisse vorliegen, als z. B. bei den übrigen Säugethieren. Ich glaube jedoch, dass die wichtigen Untersuchungen, welche Döderlein (a. a. O.) an dem Fruchtwasser von Rinderföten anstellte, auch für den Menschen in mancher Hinsicht zu verwerthen sind. Beim Rinde sind bekanntlich einfachere Verhältnisse geschaffen durch die Fortdauer der Allantoisblase und ferner dadurch, dass die Absonderung eines eiweisshaltigen Urines während der Fötalzeit ganz ausser Zweifel steht, während für den menschlichen Embryo die Mehrzahl dex Forseher 2war einen eiweissfreien Harn annimmt, jmmerhin doch Einige das Vorhandensein von Eiweiss im fötalen Harne, wenn auch nur in Spuren, behaupten. Döderlein unterwarf nun Amnioswasser und Allantoiswasser von 15 Rinderföten, die aus fast allen Monaten der Trächtigkeit stammten, einer genauen Untersuchung, bestimmte Menge derselben, Eiweissgehalt, Gesammtstickstoff, Asche, analysirte auch die letztere und stellte fest, dass zwischen den beiden Flüssigkeiten sehr bestimmte Unterschiede bestanden. Die Allantoisflüssigkeit ist zweifellos nichts anderes, als der fötale Harn; ihre absolute Menge nimmt während der ganzen Dauer der Trächtigkeit ziemlich gleichmässig zu; sie enthält zu allen Zeiten der Entwicklung reichlich Eiweiss, und zwar bedeutend mehr als das Amnioswasser. Ein Diffusionsaustausch zwischen dem Inhalte der beiden Blasen ist ausgeschlossen; dagegen spricht vor allem die ganz verschiedene Zusammensetzung der beiden Wasser. Aus der Amniosblase kann nichts in die Allantoisblase hinïberdiffundiren, da der Druck in der letzteren ein weit stärkerer ist, und umgekehrt, aus der Allantoisblase kann nichts in die Amniosblase 
diffundiren, da die Menge der Amniosflüssigkeit in der zweiten Hälfte der Trächtigkeit absolut und relativ ganz bedeutend abnimmt, während das Allantoiswasser, wie wir sahen, an Menge beständig wächst. Das Eiweiss des Allantoiswassers muss also eine andere Quelle haben, als das des Amnioswassers, und da die Allantoisblase durch den weiten und kurzen Urachus mit der Harnblase in offener Verbindung steht, so ist es klar, dass sein Eiweiss dem fötalen Urine entstammt. Nun wurde in der That im letzteren sicher Eiweiss nachgewiesen, in einem Falle 0,33 Proc., und zwar, wie Döderlein ausdrücklich betont, durch Ausfällung mit Alcohol. Durch Kochen und Versetzen mit $\mathrm{HNO}_{3}$ zeigt sich nur schwache Trübung sowohl im Harne als auch im Allantoiswasser. Es lässt sich daraus schliessen, dass hier das Eiweiss in einem anderen Zustande enthalten ist." Woher stammt aber das Eiweiss im Amnioswasser? Dass eine Diffusion aus der Allantoisblase nicht möglich ist, wurde schon gezeigt; der fötale Urin ist mithin als Quelle für das Eiweiss im Amnioswasser für alle diejenigen Thierarten, bei denen die Allantoisblase fortbesteht, sicher auszuschliessen. Bleibt also nur noch das mütterliche Blut: das Amnioswasser ist ein Transsudat aus demselben, wofür auch seine in jeder Beziehung ähnliche Zusammensetzung mit dem Blutserum spricht. Der Eiweissgehalt ist ein viel geringerer als im Allantoiswasser, er ist so gering, dass die Menge des Eiweisses als Nahrungsmittel für den Fötus gar nicht in Betracht kommt, woran selbst der beständige Befund von verschluckter Amniosflïssigkeit im Magendarme des Fötus nichts ändert. Möglich, ja wahrscheinlich ist es, dass das Wasser an sich für denselben von grosser Bedeutung ist, und Döderlein führt die Eindickung des Amnioswassers in der zwoiten Hälfte der Trächtigkeit eben darauf zurück, dass das Wasser für den Fötus verbraucht wird, während die nicht verbrauchten, zum Theile gerinnenden Eiweisskörper und schleimigen Bestandtheile wieder regurgitiren. „Zum Schlusse ist die Amniosflüssigkeit fadenziehend, schleimig und enthält zahlreiche, weiche, bräunliche Gerinnsel, wie sich deren auch in dem Inhalte des Magens finden." Dass ein Uebergang aus den mütterlichen Gefässen in das Amnioswasser mit Umgehung des fötalen Kreislaufes möglich ist, wurde durch zahlreiche Versuche von Zuntz, Wiener, Krukenberg unzweifelhaft nachgewiesen, wobei sich gleichzeitig eine erhöhte Durchlässigkeit der Eihäute in der zweiten Hälfte der Schwangerschaft herausstellte. Es drängt mithin alles darauf hin, für das Amnioswasser als einzige Quelle das mütter- 
liche Blut in Anspruch zu nehmen, auch sein Eiweiss muss demselben entstammen, und mit dieser Ueberlegung stehen unsere oben angeführten Ergebnisse in vollstem Einklange. Wie weit wir alles dies auch auf den menschlichen Fötus beziehen dürfen, das ist vorläufig freilich noch nicht anszumachen. Es müssten zunächst erneute Untersuchungen des menschlichen fötalen Urins angestellt werden, wobei die Bemerkung Döderlein's, dass die Ausfällung des Eiweisses nur durch Alcohol gelang, zu berücksichtigen wäre. Aber selbst, wenn ein Eiweissgehalt des Urins nachgewiesen werden sollte, so wissen wir doch bis jetzt über die Menge des in die Amnioshöhle entleerten Harnes gar nichts; wir wissen nicht, von welcher Zeit der Entwicklung an die fötalen Nieren absondern, wir wissen nicht, wie oft der Harn entleert wird. Es wäre denkbar, dass dies nur sehr selten geschieht, eben weil der menschliche Fötus im Gegensatze zu den mit einer Allantoisblase versehenen thierischen Föten in seiner Harnblase einen wirklichen Behälter besitzt, während die thierische Harnblase, solange der Urachus noch weit offen ist, nur einen Canal darstellt. An sich spricht vorläufig noch gar nichts dafür, dass dem Harne des Embryo ein irgendwie nennenswerther Antheil an der Bildung des Fruchtwassers zukommt.

Herrn Prof. Fehling spreche ich für seine mir überall bewiesene Güte meinen aufrichtigen Dank aus, ebenso Herrn Dr. Rossier für seine freundliche Unterstützung.

\section{Literatur - Verzeichniss.}

1) Nasse: Das Blut. Bonn 1836.

2) - Das Blut der Schwangeren. Dieses Archiv, Bd. X. Berlin 1876.

3) Andral and Gavarret: Untersuchungen über das Mengenverhältniss des Faserstoffes $u$. s. w. Uebersetzung von Walter. 1842.

4) Rodier und Becquerel: Untersuchungen über die Zusammensetzung des Blutes u. s. w. Uebersetzung von Eis enmann. 1845.

5) Kiwisch: Beiträge zur Geburtslkunde. 2. Abth. 1848.

6) - Geburtskunde. Erlangen 1853.

7) Scanzoni: Lehrbuch der Geburtskunde. Bd. I. Wien 1849.

8) - Compendium der Geburtskunde. 2. Ausg. 1861.

9) Spiegelberg und Gscheidlen: Dieses Archiv, Bd.IV. Berlin 1872.

10) Ingerslev: Centralblatt für Gynäkologie 1879, Nr. 26.

11) Fehling: Ueber Blutbeschaffenheit und Fruchtwassermenge und ihre Beziehungen zu einander. Verhandlungen der dentschen Gesellschaft für Gynälrologie 1886. I. Sitzung. 
12) P. Meger: Untersuchungen über Veränderungen des Blutes in der Schwangerschaft. Dieses Archiv 1887, Bd. XXXI, Heft 1.

13) C. Reinl: Untersuchungen über den Hämoglobingehalt des Blutes in den letzten Monaten der Gravidität und im Wochenbett. "Beiträge zur Geburtshülfe und Gynälkologie.:

14) K. Winkelmann: Hämoglobinbestimmungen bei Schwangeren und Wöchnerinnen. Inaugural-Dissertation. Heidelberg 1888.

15) Leichtenstern: Untersuchungen über den Hämoglobingehalt des Blutes in gesunden und kranken Zuständen. Leipzig 1878.

16) D. Scherenziss: Untersuchungen über das fötale Blut im Momente der Geburt. Inaugural-Dissertation. Dorpat 1888.

17) Fr. Krüger: Ueber das Verhalten des fötalen Blutes im Momente der Geburt. Inaugural-Dissertation. Dorpat 1886.

18) Fleischl: Das Hämometer. Medicinische Jahrbücher der k. k. Gesellschaft der Aerzte in Wien 1885.

19) - Regeln für den Gebrauch des Hämometer. Wien 1886.

20) Herrmann: Handbuch der Physiologie, Bd. IV, 1. Theil.

21) R. Stierlin: Blatkörperchenzählungen und Hämoglobinbestimmungen bei Kindern. Inaugural-Dissertation. Leipzig 1889.

22) Liebermeister: Sammlung klinischer Vorträge (Volkmann) Nr. 110.

23) Sahli: Zur Diagnose und Therapie anämischer Zustände. Correspondenzblatt für Schweizer Aerzte 1886, Nr. 20 u. 21.

24) Quincke: Zur Physiologie und Pathologie des Blutes. Deutsches Archiv für klinische Medicin 1883, Bd. XXX.

25) P. Müller: Handbuch der Geburtshülfe, Bd. I; Bd. II, 2. Hälfte.

26) Cohnstein: Pflüger's Archiv, Bd. XXXIV, S. 233.

27) Vierordt: Die Anwendung des Spectralapparates zur Messung und Vergleichung des farbigen Lichtes. Tübingen 1871.

28) - Die Anwendung des Spectralapparates zur Photometrie der Absorptionsspectren. Tübingen 1873.

29) Fehling: Dieses Archiv, Bd. VI, S. 385; Bd. VII, S. 143 ; Bd. IX, S. 313; Bd. X, S. 391; Bd. XI, S. 523; Bd. XII, S. 331; Bd. XVI, S. 286.

30) Preyer: Specielle Physiologie des Embryo. Leipzig 1885.

31) Ahlfeld: Berichte und Arbeiten, Bd. II, S. 24; Bd. III, S. 144.

32) - Centraiblatt für Gynäkologie 1877, S. 205.

33) Lom er: Centralblatt für Gynäkologie 1887, S. $537 \mathrm{ff}$.

34) Sandmeyer: Ueber den Eiweissgehalt des Fruchtwassers. InanguralDissertation. Marburg 1888.

35) Fehling: Das Dasein vor der Geburt. 1887. S. 9 u. 10.

36) $\mathrm{Z}$ weifel: Dieses Archiv, Bd. VII, S. 475; Bd. IX, S. 291; Bd. X, S. 400 ; Bd. XII, S. 235 ; Bd. XIII, S. 462 . 